\title{
Graphitic carbon nitride materials: variation of structure and morphology and their use as metal-free catalysts
}

\author{
Arne Thomas, ${ }^{a}$ Anna Fischer, ${ }^{a}$ Frederic Goettmann, ${ }^{a}$ Markus Antonietti, ${ }^{* a}$ Jens-Oliver Müller, ${ }^{b}$ Robert Schlögl ${ }^{b}$ \\ and Johan M. Carlsson ${ }^{c}$
}

Received 7th January 2008, Accepted 6th May 2008

First published as an Advance Article on the web 10th July 2008

DOI: $10.1039 / \mathrm{b800274f}$

Graphitic carbon nitride, $\mathrm{g}-\mathrm{C}_{3} \mathrm{~N}_{4}$, can be made by polymerization of cyanamide, dicyandiamide or melamine. Depending on reaction conditions, different materials with different degrees of condensation, properties and reactivities are obtained. The firstly formed polymeric $\mathrm{C}_{3} \mathrm{~N}_{4}$ structure, melon, with pendant amino groups, is a highly ordered polymer. Further reaction leads to more condensed and less defective $\mathrm{C}_{3} \mathrm{~N}_{4}$ species, based on tri-s-triazine $\left(\mathrm{C}_{6} \mathrm{~N}_{7}\right)$ units as elementary building blocks. High resolution transmission electron microscopy proves the extended two-dimensional character of the condensation motif. Due to the polymerization-type synthesis from a liquid precursor, a variety of material nanostructures such as nanoparticles or mesoporous powders can be accessed. Those nanostructures also allow fine tuning of properties, the ability for intercalation, as well as the possibility to give surface-rich materials for heterogeneous reactions. Due to the special semiconductor properties of carbon nitrides, they show unexpected catalytic activity for a variety of reactions, such as for the activation of benzene, trimerization reactions, and also the activation of carbon dioxide. Model calculations are presented to explain this unusual case of heterogeneous, metal-free catalysis. Carbon nitride can also act as a heterogeneous reactant, and a new family of metal nitride nanostructures can be accessed from the corresponding oxides.

\section{Introduction: Literature review and an admittedly personal access to $\mathrm{g}-\mathrm{C}_{3} \mathrm{~N}_{4}$}

Carbon nitrides are promising candidates to complement carbon in materials applications. Diamond-like $\beta-\mathrm{C}_{3} \mathrm{~N}_{4}$ is predicted to be of similar hardness and low compressibility as diamond. ${ }^{1,2}$ At

${ }^{a}$ Max Planck Institute of Colloids and Interfaces, Research Campus Golm, Am Muehlenberg 1, D-14476 Golm, Germany.E-mail: pape@mpikg.mpg. de

${ }^{b}$ Fritz-Haber-Institute of the Max-Planck-Society, Department of Inorganic Chemistry, Faradayweg 4-6, D-14195 Berlin, Germany

${ }^{c}$ Fritz-Haber-Institute of the Max-Planck-Society, Theory Department, Faradayweg 4-6, D-14195 Berlin, Germany ambient conditions, graphitic $\mathrm{C}_{3} \mathrm{~N}_{4}\left(\mathrm{~g}-\mathrm{C}_{3} \mathrm{~N}_{4}\right)$ is however regarded to be the most stable allotrope, and there are a large number of reports in the literature approaching the synthesis of different modifications of this material (see Table 1). A very careful discussion of the history of chemical approaches towards diverse $\mathrm{C}_{3} \mathrm{~N}_{4}$ derivatives was recently given by Kroke and Schwarz ${ }^{3}$ and Fuess et al. ${ }^{4} \mathrm{~A}$ polymeric derivative was made by Berzelius and named by Liebig in 1834 as "melon", and is regarded as one of the oldest synthetic polymers as such. ${ }^{5}$

Closer insights into the structure of these compounds were described by Franklin as early as 1922 . He found that the empirical composition of melon derivatives derived from mercuric thiocyanate varied with the method of preparation, and

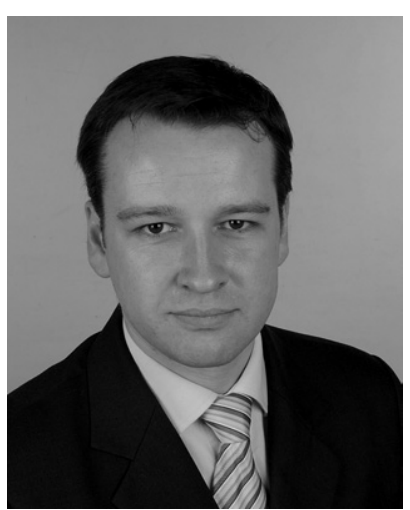

Arne Thomas
Arne Thomas received his diploma in chemistry from the Philipps University Marburg and his PhD from the University of Potsdam and the Max Planck Institute of Colloids and Interfaces with Professor Antonietti in 2003. After a postdoctoral fellowship with Professor Galen Stucky at UCSB he now heads a group at the Max Planck Institute of Colloids and Interfaces researching meso/microporous polymers and organic frameworks.

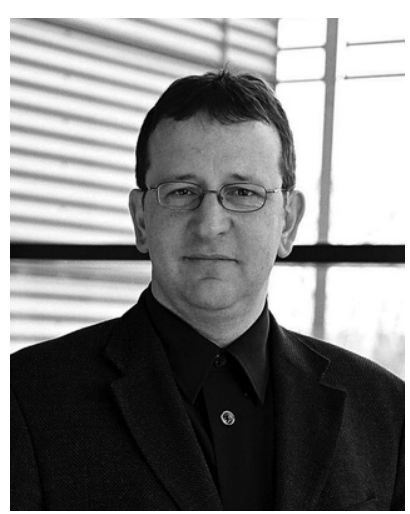

Markus Antonietti
Markus Antonietti received his scientific education at the University of Mainz. Since 1993, he has been Director of the Department of Colloid Chemistry of the Max Planck Institute of Colloids and Interfaces. His scientific interests are mainly focussed on novel materials with unusual properties and nanostructures. His current activities are in using materials science to promote raw material and energy changes. 


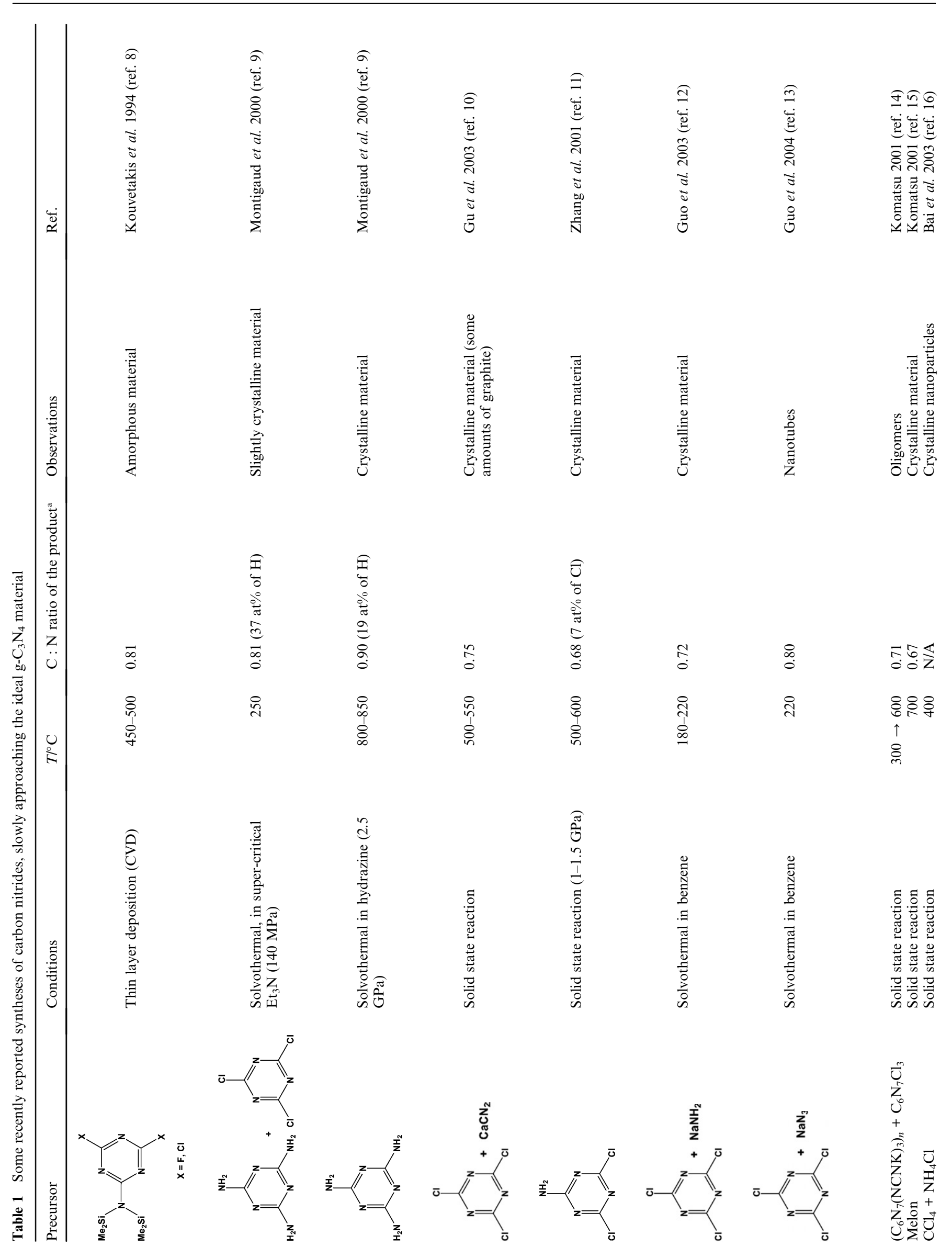



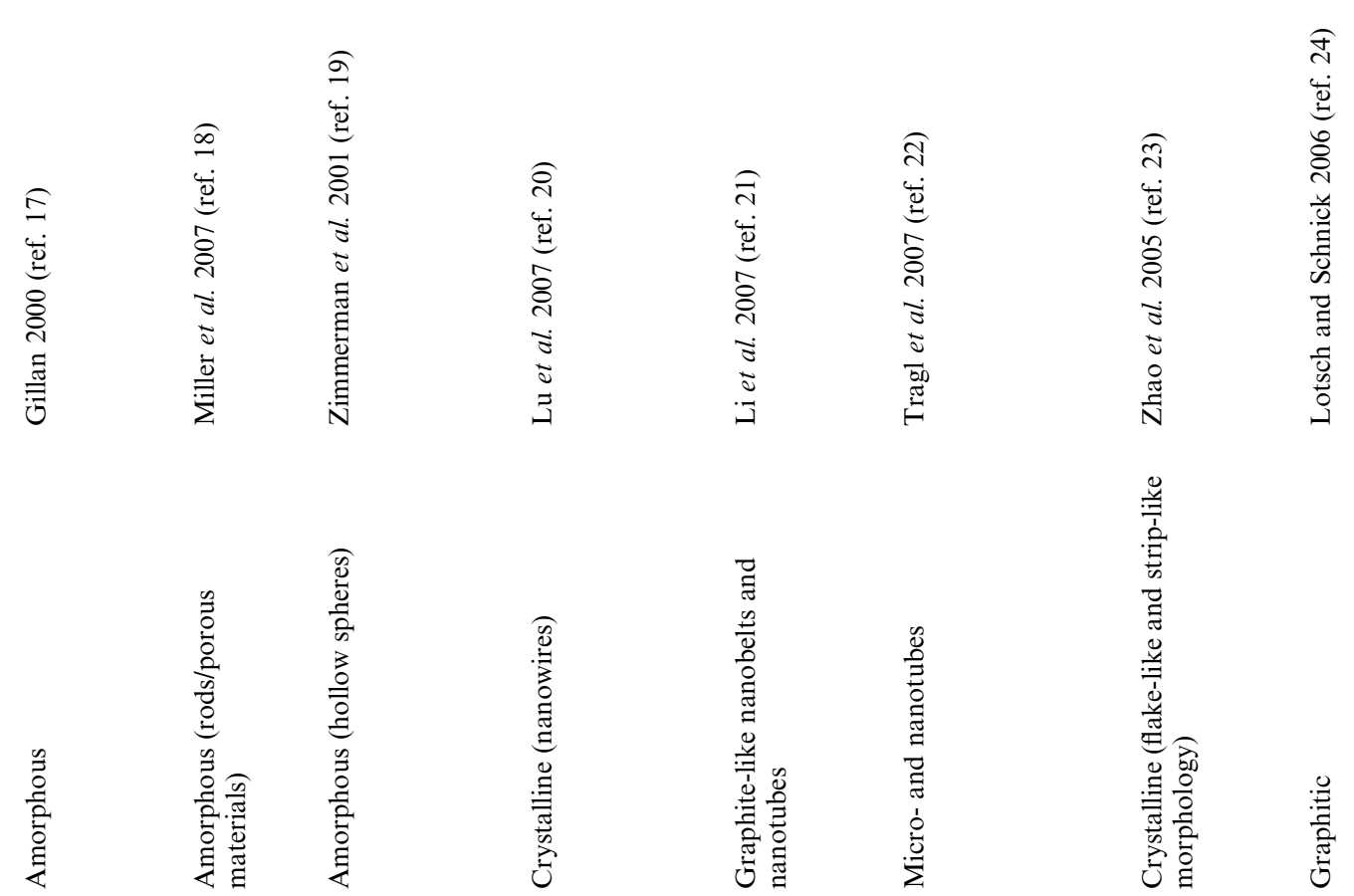

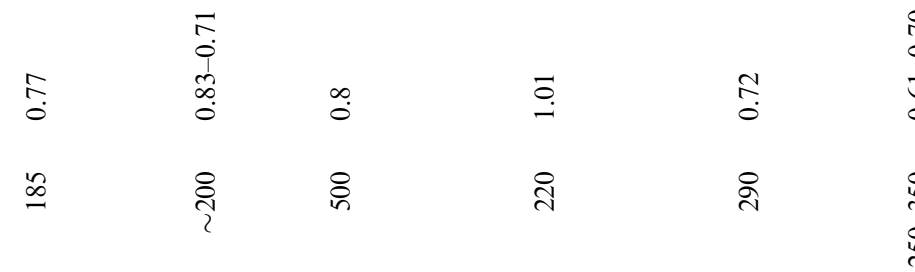

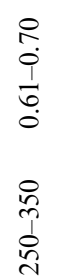

$\stackrel{?}{:} \quad \stackrel{0}{0}$

:

$\stackrel{\substack{n \\ \wedge}}{1}$
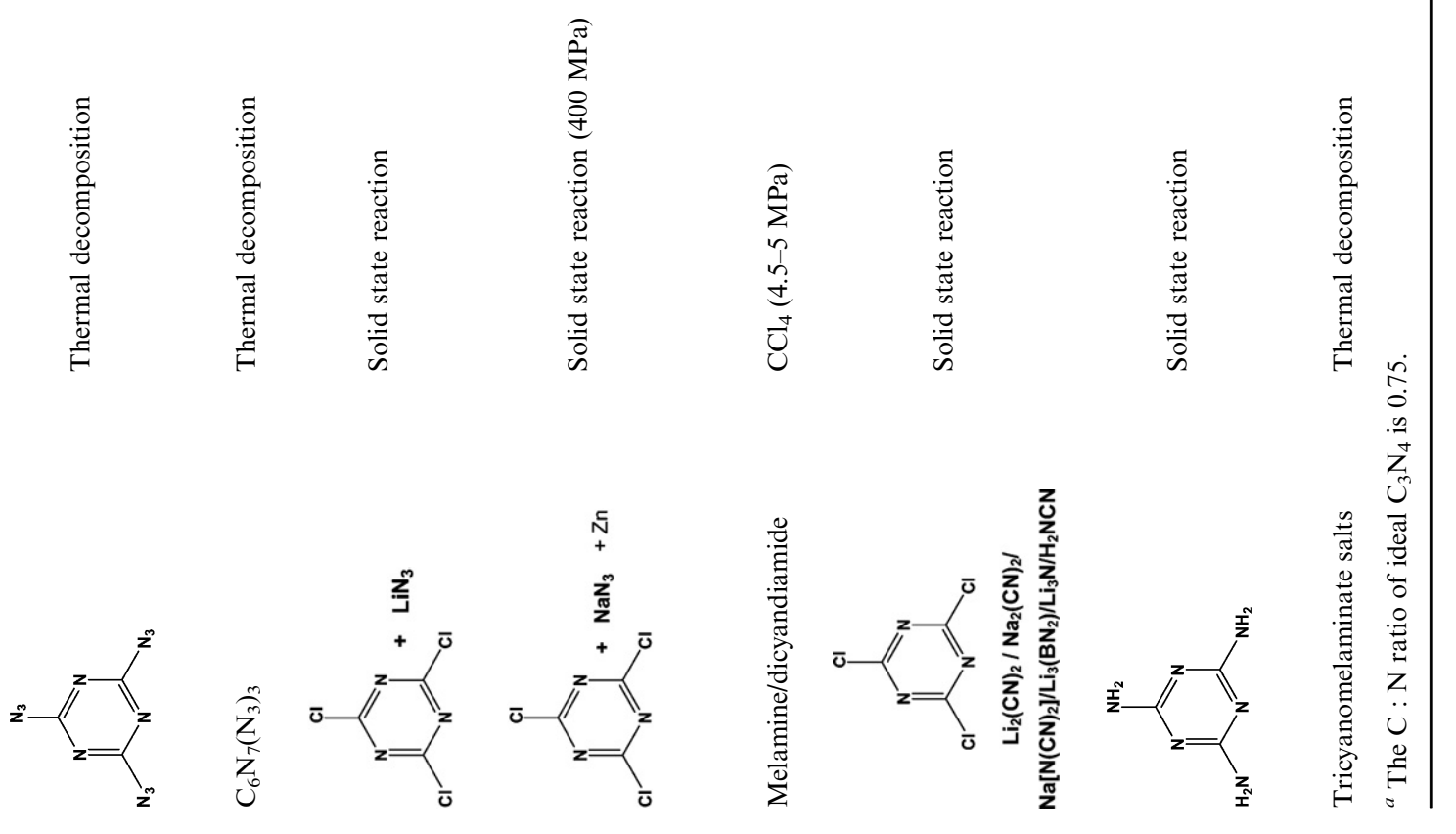
hydrogen content varied from 1.1 to $2.0 \mathrm{wt} \%{ }^{6}$ Based on these findings it was stated that probably not one single structure should be assigned to melon as it is more likely a mixture of polymers of different sizes and architectures. ${ }^{7}$

After 170 years, the diverse syntheses of $\mathrm{g}^{-} \mathrm{C}_{3} \mathrm{~N}_{4}$ like materials cover a broad set of diverse carbon- and nitrogen-rich starting compounds. For example, Kouvetakis et al. decomposed derivatized melamine precursors at $400-500{ }^{\circ} \mathrm{C}$ and obtained an amorphous carbon nitride with about the correct composition and a broad graphitic stacking peak. ${ }^{8}$ Montigaud et al. reported on the solvothermal condensation of melamine with cyanurchloride, which also worked at larger scales. ${ }^{9}$ Condensation performed at $250^{\circ} \mathrm{C}$ and $140 \mathrm{MPa}$ revealed a weakly condensed product with low order and many pendant amino groups. Heating melamine in presence of hydrazine to $800{ }^{\circ} \mathrm{C}$ at $2.5 \mathrm{GPa}$ resulted in carbonitrides with almost perfect graphitic stacking, but a high depletion of nitrogen, and there was too little remaining nitrogen to show a regular distribution. This work was resumed by Qian et al. who synthesized carbon nitrides by condensing cyanurchloride and calcium cyanamide ${ }^{10}$ and identified only a very small temperature window between 500 and $600{ }^{\circ} \mathrm{C}$ to optimize order and composition of the potentially final $\mathrm{g}_{-} \mathrm{C}_{3} \mathrm{~N}_{4}$. Wolf et al. used 2-amino-4,6-dichlorotriazine as a precursor and obtained in a high pressure-high temperature approach a close-to-crystalline graphitic $\mathrm{C}_{3} \mathrm{~N}_{4}$ derivative, where the generated $\mathrm{HCl}$ played the role of a template to fill the nitridic in-plane pores of a triazine-based condensation pattern. ${ }^{11}$ The structure of Wolf products was quite refined, as the system exhibited both regular in-plane packing of the nitridic triazinebased pores and X-ray patterns which could be quantitatively assorted. Xie et al. were able to make $\mathrm{g}-\mathrm{C}_{3} \mathrm{~N}_{4}$ from cyanurchloride and sodium amide solvothermally in benzene by heating to about $200{ }^{\circ} \mathrm{C}$ for $8-12 \mathrm{~h} .{ }^{12}$ The same group reported on the production of carbon nitride nanotubes by a similar reaction from cyanurchloride and sodium azide. ${ }^{11}$ Graphitic packing in those samples was less pronounced, which however may also be due to the nanostructure.

Komatsu ${ }^{14}$ reported on a highly ordered model carbon nitride, $\mathrm{C}_{91} \mathrm{H}_{14} \mathrm{~N}_{124}$. The same group also reported a highly crystalline species which they called "high molecular weight" melon. ${ }^{15}$ The X-ray diffractograms of both observed species were-for polymeric materials - highly textured. Another benchmark step towards better defined and organized graphitic $\mathrm{C}_{3} \mathrm{~N}_{4}$ systems was published by Schnick et al. ${ }^{25}$ who were able to isolate and solve the crystal structure of another intermediate, 2,5,8-triaminotri-s-triazine, or melem $\left(\mathrm{C}_{6} \mathrm{~N}_{10} \mathrm{H}_{6}\right)$. Melem was found to be a rather stable intermediate, but further heating, in contrast to the Komatsu experiments, only resulted in poorly defined amorphous graphitic $\mathrm{C}_{3} \mathrm{~N}_{4}$, as reported by the authors. In a recent paper, the same group was able to clarify the structure of a highly defined melon polymer, ${ }^{26}$ thus providing further evidence that already the polymeric species can exhibit high local crystal packing. We regard these described substances as a closeto-ideal model case of the polymeric melon structure.

Physical and chemical vapor deposition methods to synthesize thin films are also described quite often ${ }^{27-29}$ but all of them are dogged by the elimination of the very stable $\mathrm{N}_{2}$, which results in disordered, quite carbon-rich materials. As ${ }^{2}-\mathrm{C}_{3} \mathrm{~N}_{4}$ is a potentially useful substitute for amorphous and graphitic carbon in a variety of material science applications, e.g. as a catalyst or an active catalytic support, as a membrane material or for gas storage,$^{30}$ novel procedures to defined carbon nitride materials and a better understanding of the reaction sequence are ongoing topics of research.

Both triazine and tri-s-triazine were discussed as tectonic units to constitute potential allotropes of $\mathrm{g}_{-} \mathrm{C}_{3} \mathrm{~N}_{4}$, which differ in their stability - due to the different electronic environment of the $\mathrm{N}$ atom - and the sizes of the nitride pores, as seen in Fig. 1.

Kroke et al. ${ }^{31}$ calculated on the basis of density-functional theory (DFT) that the tris-s-triazine based structure is $30 \mathrm{~kJ}$ $\mathrm{mol}^{-1}$ more stable. Indeed, all g- $\mathrm{C}_{3} \mathrm{~N}_{4}$ intermediates and derivatives synthesized in our experiments are based on cyamelluric tri-s-triazine building blocks, confirming that this tecton is the most stable local connection pattern under the given reaction conditions.

We will focus below on the material synthesis based on polycondensation of the liquid precursors (cyanamide, dicyandiamide), as they allow for convenient shaping towards a variety of<smiles>CN(C)c1nc(N(C)C)nc(N(c2nc(N(C)C)nc(N(C)C)n2)c2nc(N(c3nc(N(C)C)nc(N(C)C)n3)c3nc(N(C)C)nc(N(C)C)n3)nc(N(c3nc(N(C)C)nc(N(C)C)n3)c3nc(N(C)C)nc(N(C)C)n3)n2)n1</smiles>

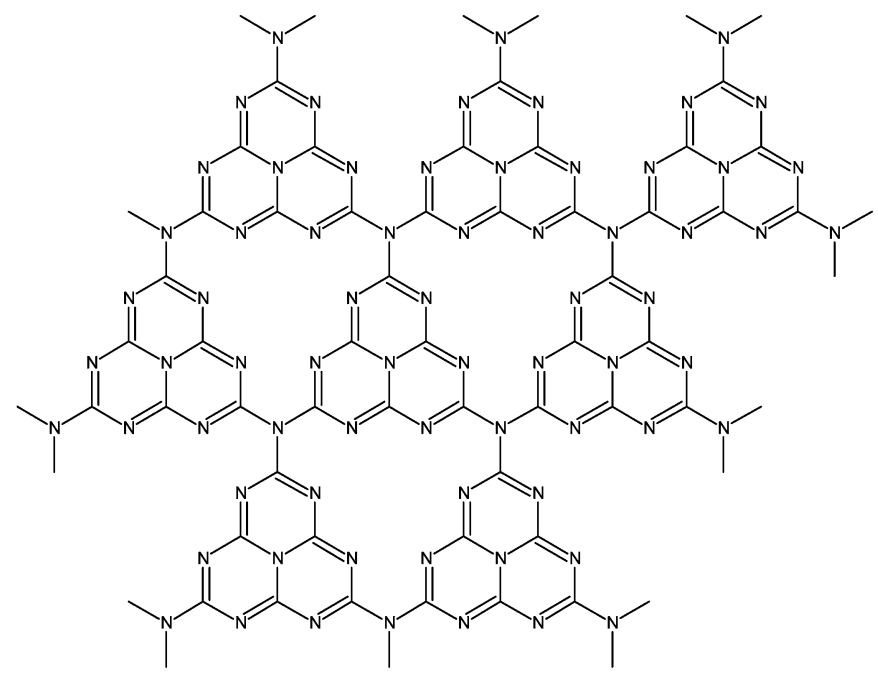

Fig. 1 Triazine- (left) and tri-s-triazine-based connection patterns (right) of potential g- $\mathrm{C}_{3} \mathrm{~N}_{4}$ allotropes. 
nanostructures, such as thin films and coatings, nanoparticles and nanorods, or mesoporous monoliths. This access via an easy accessible liquid monomer and a polymerization process is certainly one of the great advantages of $\mathrm{C}_{3} \mathrm{~N}_{4}$ materials, making it an attractive choice for a variety of applications of carbon-like materials. This will be delineated in more detail below.

\section{Synthesis and bulk structures of differently condensed carbon nitrides}

Thermoanalytical methods (TGA, DSC) in combination with XRD were used to characterize the intermediate steps along the condensation of the molecular precursor, thus quantifying the early Berzelius experiments. ${ }^{32}$ The reaction is a combination of a polyaddition and polycondensation scheme where the precursors are first condensing towards melamine. The second step is a condensation where ammonia is eliminated; consequently, the products differ when performed in closed and open reaction flasks. Up to $350{ }^{\circ} \mathrm{C}$, essentially melamine based products are found, while the tris-s-triazine forms via melamine rearrangements at round $390{ }^{\circ} \mathrm{C}$. Condensation of this unit to polymers, networks and potentially the final polymeric $\mathrm{C}_{3} \mathrm{~N}_{4}$ occurs at around $520{ }^{\circ} \mathrm{C}$, with the material becoming unstable slightly above $600{ }^{\circ} \mathrm{C}$. Heating to $700{ }^{\circ} \mathrm{C}$ results in the residue-free disappearance of the material via generation of nitrogen and cyano fragments. This sequence is schematically shown in Scheme 1. One big practical problem in such syntheses is the easy sublimation of melamine at elevated temperatures. This can be suppressed to larger extends when the melamine is transiently generated in coexistence with other species, where H-bridges obviously retard the melamine. Therefore it is recommended to use dicyandiamide as a precursor and promote a rather rapid passage of the melamine phase to increase the mass efficiency in the polymerization process.

At about $390{ }^{\circ} \mathrm{C}$, the cyameluric nucleus, $\mathrm{C}_{6} \mathrm{~N}_{7}$, forms via rearrangement of melamine units, as previously reported by Schnick et al. for the synthesis of melem. ${ }^{25}$ This condensation product is a rather stable intermediate and can be safely isolated
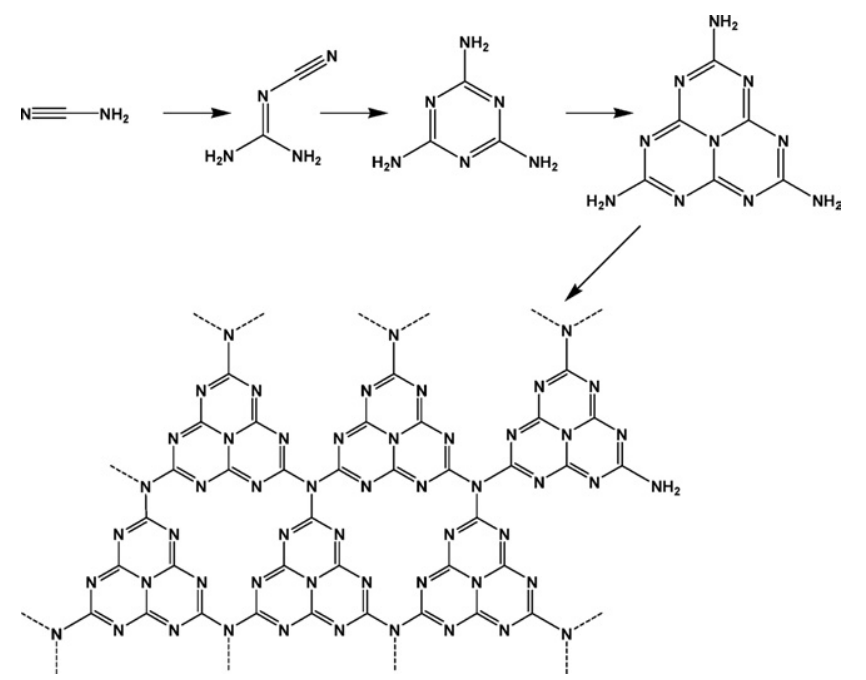

Scheme 1 Reaction path for the formation of graphitic $\mathrm{C}_{3} \mathrm{~N}_{4}$ starting from cyanamide. by stopping the reaction at $400{ }^{\circ} \mathrm{C}$ in closed glass tubes under high partial pressures of ammonia. The equilibrium shifts to the oligomeric or polymeric species when the reaction processes in open crucibles poor in ammonia, as can be proven by a higher mass loss and the corresponding higher $\mathrm{C}: \mathrm{N}$ ratio in elemental analysis. Heating of the pre-condensed products over $500{ }^{\circ} \mathrm{C}$ results in further elimination of significant amounts of ammonia and formation of a more condensed $\mathrm{C}_{3} \mathrm{~N}_{4}$ polymer.

The reaction steps of the polyaddition and condensation reactions have been further studied by ab initio calculations in order to clarify the reaction path in more detail. The calculations are based on DFT using a plane wave basis set with an energy cut-off of $550 \mathrm{eV}$ and ultrasoft pseudopotentials. ${ }^{33}$ Melamine and melem are molecular crystals, where the molecules have strong covalent bonds inside the molecular building blocks, while the crystal is held together by weak interactions, such as hydrogen bonding and van der Waals interactions. The intramolecular bonds give the dominant contribution to the cohesive energy and we have therefore concentrated on total energy calculations for the molecules. The cohesive energies in Fig. 2 are calculated for the free molecules and free standing sheets rather that a $3 \mathrm{D}$ molecular crystal.

The calculations reveal that the cohesive energy of the molecules increase along the polyaddition path as shown in Fig. 2, supporting the conclusions that melamine is formed from the cyanamide precursor upon heating. It has been debated whether further condensation proceeds via polymerization of melamine to form a $\mathrm{C}_{3} \mathrm{~N}_{4}$ sheet structure based on triazine units, or if the melamine molecules first form melem molecules that are subsequently polymerized into a $\mathrm{C}_{6} \mathrm{~N}_{8}$ sheet structure based on tri$s$-triazine units. Experiments indicated that melam (melamine dimers) are formed as metastable intermediates and that melem is the likely product after polymerization of melamine. ${ }^{34}$ This in agreement with our DFT calculations that show that the cohesive energy increases from melamine via melam to melem. This suggests that the polymerization continues via the tri-s-triazine path and the next step is the connection between adjacent molecules in the melem crystal to form dimelem molecules. The dimelem molecules can then undergo further condensation into melon, a linear polymer of tri-s-triazine units, by further release of $\mathrm{NH}_{3}$ molecules. The calculations indicate that the shape of the

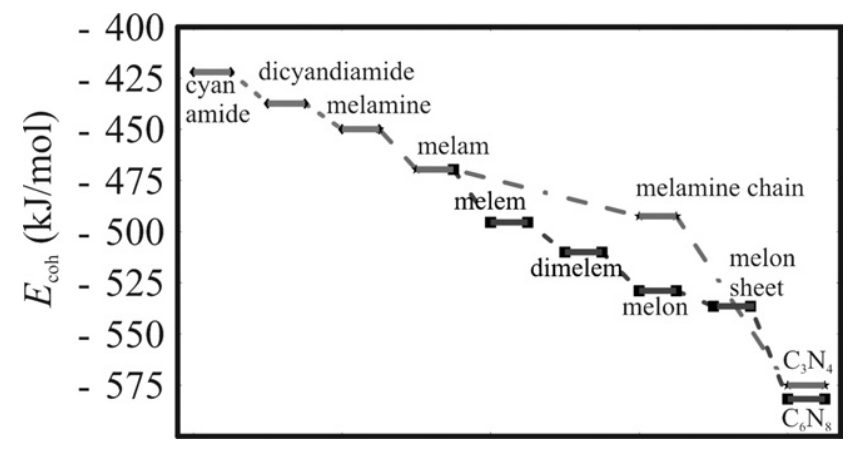

Fig. 2 Calculated energy diagram for the synthesis of carbon nitride. The starting precursor cyanamide is condensing into melamine. Further condensation can then proceed via the triazine route (dash-dot line) to $\mathrm{C}_{3} \mathrm{~N}_{4}$, or melamine can form melem and then follow the tri-s-triazine route (dashed line) to form $\mathrm{C}_{6} \mathrm{~N}_{8}$. The energies are presented per atom. 
melon chain is determined by a competition between the energy gain by extending the $\pi$-electron system into a linear chain and the repulsion between the lone-pair electrons at the $\mathrm{N}$ atom on the edge of the tri-s-triazine unit, as has been discussed recently. ${ }^{26,35}$ The linear chain is therefore strongly buckled, since the tri-s-triazine molecules tries to maximize the distance between the $\mathrm{N}$ atoms on the edge of adjacent molecules. It was recently proposed that the melon chain is instead constructed from dimers where the top corner is connected to a side corner, giving the melon chain a staircase shape. ${ }^{26,35}$ Our calculations show that the melon in this dimerized form is more stable by $20 \mathrm{~kJ}$ per mol tri-s-triazine molecules than a linear chain.

The final step of the polymerization is the formation of carbon nitride sheets by fusing the melon chains. There are a number of ways to connect the melon chains into a sheet like structure and the actual form depend on the degree of condensation. The first possibility is connecting the melon chain two-by-two, where every second melon chain is inverted. ${ }^{26}$ This forms a structure where the triangular tri-s-triazine molecules fit like a lock and key into each other and the structure is held together by hydrogen bonds between the $\mathrm{NH}_{2}$ groups and the $\mathrm{N}$ edge atoms. This melon sheet structure is indeed more stable than the isolated melon chains by $63 \mathrm{~kJ}$ monomol ${ }^{-1}$. The formation energy of a melon sheet with respect to graphite and $\mathrm{N}_{2}$ is furthermore slightly negative $\Delta E_{\text {melon sheet }}(T=0 \mathrm{~K})=16 \mathrm{~kJ} \mathrm{~mol}^{-1}$ tri-striazine units indicating that it is a stable structure, such that it may be considered as the condensed structure of melon. Releasing another $\mathrm{NH}_{3}$ molecule per tri-s-triazine unit would remove the remaining hydrogen to form a pure carbon nitride material with $\mathrm{C}_{6} \mathrm{~N}_{8}$ stoichiometry. The cohesive energy increases significantly upon removing the remaining hydrogen, such that $\mathrm{C}_{6} \mathrm{~N}_{8}$ would theoretically be the most stable form of carbon nitride. However, there may be kinetic hindrance for the connection of the tri-s-triazine units into the ordered pattern of the $\mathrm{C}_{6} \mathrm{~N}_{8}$ structure in Fig. 1, starting from the melon sheet structure, since every second melon chain is connected in the opposite direction.

In addition, the $\mathrm{N}$ repulsion becomes much more severe due to the closer proximity of the tri-s-triazine units in the sheet structure, such that the $\mathrm{C}_{6} \mathrm{~N}_{8}$ sheets are heavily buckled. Our calculations suggests that an infinite $\mathrm{C}_{6} \mathrm{~N}_{8}$ sheet would have a sinuous form extending in three directions across the sheet with a maximal amplitude of $0.7 \AA$. The buckling increases the $\mathrm{N}-\mathrm{N}$ distance to from $2.44 \AA$ in the flat sheet to within the range of 2.52-2.72 $\AA$ in the buckled sheet. This diminishes the $\mathrm{N}-\mathrm{N}$ repulsion that gives a net energy gain by $11 \mathrm{~kJ} \mathrm{~mol}^{-1}$ per neighboring $\mathrm{N}-\mathrm{N}$ pair, as compared to a flat $\mathrm{C}_{6} \mathrm{~N}_{8}$ sheet. The infinite sheet imposes limitations on the buckling and similar calculations for a finite $\mathrm{C}_{6} \mathrm{~N}_{8}$ sheet suggested an aperiodic structure and a slightly larger energy gain by the buckling. ${ }^{35}$

The coupled structural changes of the involved phase transitions throughout condensation are nicely followed by temperature dependent WAXS experiments, depicted in Fig. 3.

The strongest peak at $27.3^{\circ}$ is a characteristic interplanar stacking peak of aromatic systems, indexed for graphitic materials as the (002) peak. A stacking distance of the aromatic units of $d=0.326 \mathrm{~nm}$ can be calculated. This stacking is significantly more tight than the packing in carbon with graphene units $(d=0.353 \mathrm{~nm})$ and even $3 \%$ more dense than the packing in

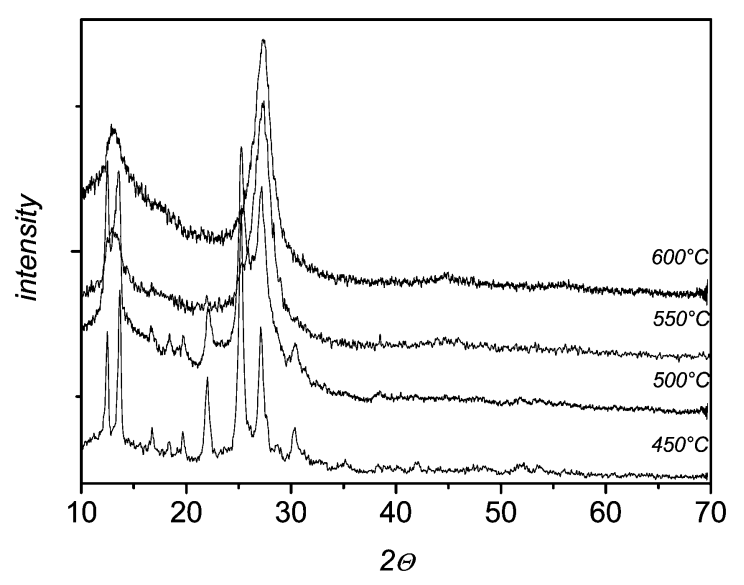

Fig. 3 WAXS measurements characterizing the transition from polymeric $\mathrm{C}_{3} \mathrm{~N}_{4}$ to the first $\mathrm{g}-\mathrm{C}_{3} \mathrm{~N}_{4}$ intermediate. The reaction was stopped immediately after the given temperature was reached.

crystalline graphite, which exhibits $d=0.335 \mathrm{~nm} .{ }^{36}$ The higher packing density perpendicular to the layers for aromatic systems with heteroatom substitution is well understood and can be attributed to the localization of the electrons and stronger binding between the layers. This peak position is also in agreement with previous reports on high quality melon materials.

A pronounced additional peak is found at $13.1^{\circ}$, corresponding to a distance $d=0.675 \mathrm{~nm}$. Also this peak is typical of more oriented melons ${ }^{12,37}$ but is rather differently interpreted by various authors. Based on the electron microscopy evidence reported below, the $13.1^{\circ}$ small angle peak presumably relates to an in-plane structural packing motif, such as the hole-to-hole distance of the nitride pores in the crystal. This distance is only slightly below the size of one tris-s-triazine unit $(c a .0 .73 \mathrm{~nm})$, indicative of the already discussed buckling. Komatsu for instance has indexed the $13.1^{\circ}$ and $27.3^{\circ}$ peaks in a more complicated fashion. ${ }^{15}$

XPS measurements (Fig. 4) can reveal further details about this carbon nitride polymer. The $\mathrm{C} 1 \mathrm{~s}$ binding energy shows mainly one carbon species with a binding energy of $288.2 \mathrm{eV}$, corresponding to a $\mathrm{C}-\mathrm{N}-\mathrm{C}$ coordination. In the $\mathrm{N} 1 \mathrm{~s}$ spectrum several binding energies can be separated. The main signal shows occurrence of $\mathrm{C}-\mathrm{N}-\mathrm{C}$ groups $(398.7 \mathrm{eV})$ and tertiary nitrogen $\mathrm{N}-(\mathrm{C})_{3}$ groups $(400.1 \mathrm{eV})^{38}$ in about the expected ratio. Deconvolution of the XPS signals also reveals a weak additional signal at $401.4 \mathrm{eV}$, indicative of amino functions carrying hydrogen $(\mathrm{C}-\mathrm{N}-\mathrm{H})$. It is however important to underline that the peak of tertiary amines is stronger by a factor of 4 than that of these hydrogen bound amines. This proves a degree of condensation well beyond the linear polymer melon structure, which would possess no tertiary amines at all. The peak at $404.1 \mathrm{eV}$ is attributed to charging effects.

Integration of the $\mathrm{C}$ and $\mathrm{N}$ signals gave an atomic $\mathrm{C} / \mathrm{N}$ ratio of 0.71 , indicating $5 \%$ of nitrogen excess compared to the theoretical value, which again can be attributed to the fact that the amine condensation is still rather far from complete in the material made in this way. This slight surplus of amine is regularly reported even for highly condensed melon species and is to be taken as a signature that the material is indeed a highly ordered, polymeric melon, but so far not the idealized, single crystalline $\mathrm{g}-\mathrm{C}_{3} \mathrm{~N}_{4}$. 

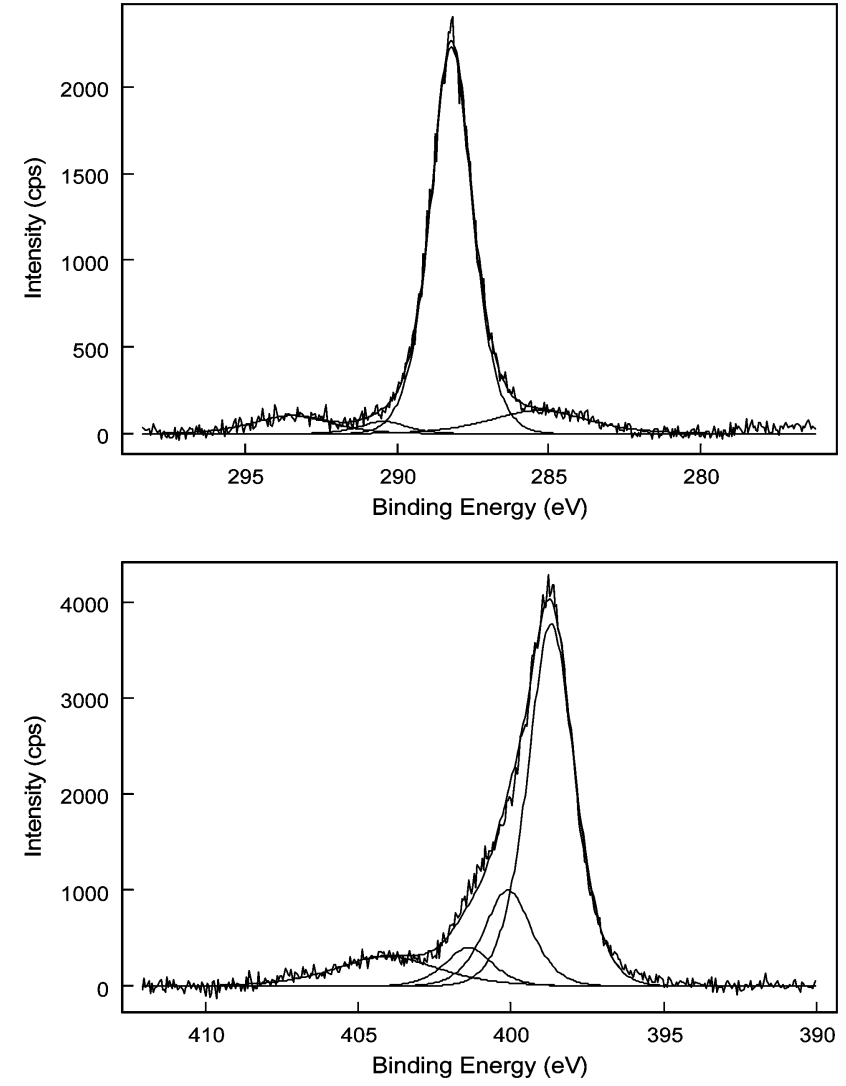

Fig. 4 XPS spectra of the $\mathrm{C}_{3} \mathrm{~N}_{4}$ synthesized at $550{ }^{\circ} \mathrm{C}$. Shown are the $1 \mathrm{~s}$ binding energies of carbon (top) and nitrogen (bottom).

Elemental analyses were performed by many authors (see Table 1) and support incomplete condensation. An average $\mathrm{C} / \mathrm{N}$ ratio of 0.72 is usually found (theoretical value of $\mathrm{C}_{3} \mathrm{~N}_{4}=0.75$ ), as well as small but significant amounts of hydrogen $(2 \%)$ from uncondensed amino functions. It is very difficult to lower the hydrogen content by simple condensation beyond this limit, pointing to an energetic hindrance of the final elimination steps. The maximum operation window without depleting the structure of nitrogen is limited to $600{ }^{\circ} \mathrm{C}$, and order can only be improved by isothermally tempering it in a sealed quartz ampoule at $600{ }^{\circ} \mathrm{C}$, e.g. for $10 \mathrm{~h}$. Upon doing this, a significant structural improvement of the material is obtained (see Fig. 5), indicative of some residual dynamics in the material. A much better interlayer organization can be generated by tempering, accompanied by a compression of the average interlayer distance towards smaller $d$ values $(d=0.319 \mathrm{~nm})$. This is about the smallest value for the packing of aromatic units ever found. In addition, the in-plane peak is also narrowed, has relatively weakened and has shifted to larger distances (from $0.675 \mathrm{~nm}$ to $0.689 \mathrm{~nm}$ ). Also the stretching modes of the skeletal $\mathrm{g}-\mathrm{C}_{3} \mathrm{~N}_{4}$ network in the FTIR spectrum are better resolved in this tempered material, probably due to a decoupling of the vibrational modes by the better organization.

While all the weakly condensed, "polymeric" melon species suffered a rapid structural decomposition in the intense electron beam, the tempered and better organized material is stable enough to allow for HRTEM and EELS measurements. In order to minimize electron beam damage, investigations have to be carried out using low beam intensity and short acquisition times

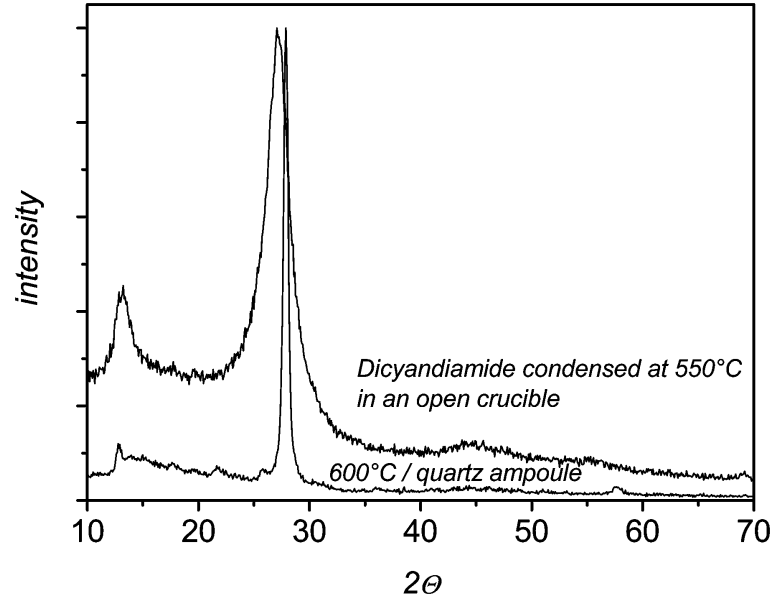

Fig. 5 XRD patterns of the synthesized carbon nitride materials prior to and after a structural optimization step at $600{ }^{\circ} \mathrm{C}$. The interlayer reflection has shifted to higher angles in the tempered structure, and additional scattering peaks are found.

for image recording. Fig. 6a gives a representative overview of such a material after heat treatment to $600{ }^{\circ} \mathrm{C}$. Several crystallites with platelet-like morphologies in the size range of $500 \mathrm{~nm}$ are visible. A HRTEM micrograph of the material is given in Fig. 6b. The acquired image indicates a close to hexagonal arrangement of the scaffolding tri-s-triazine structure with apparent plane distances between 0.58 and $0.65 \mathrm{~nm}$ (Fig. 6b). A perfect crystalline material consisting of tri-s-triazine units would reveal a sixfold or threefold symmetry, with distances of $d=0.72 \mathrm{~nm}$. The slightly smaller distance in the picture is potentially due to a tilted view onto the tris- $s$-triazine stacks to allow visualization of the pores. Fig. $6 \mathrm{c}$ shows the side view of several intergrown domains illustrating the graphite-like stacking in the material. The material is rich in defects, i.e. it is an as-grown polymer material and not a single crystal. Measurements of the inter-layer distance from the HRTEM micrograph reveals a spacing of $d=$ $0.327 \mathrm{~nm}$, which is in good agreement with the XRD data. In the direction orthogonal to the layers, the power spectra reveal a projected periodicity of $d=0.697 \mathrm{~nm}$, corresponding to the size of the tri-s-triazine units in a buckled mode. The stacking of the tri-s-triazine units in the different domains is however less regular. This is indicated by the absence of corresponding defined peaks in the power spectra. Instead of diffraction spots, streaks in the direction perpendicular to the layers are visible. The in-plane and inter-layer spacings differ slightly from domain to domain.

The core-level EELS spectrum of the samples (Fig. 7) shows that the system is practically exclusively composed of $\mathrm{sp}^{2}$-hybridized carbon and nitrogen atoms, as indicated by the presence of the $1 \mathrm{~s} \rightarrow \pi^{*}$ transition for both elements. The carbon-K ionization edge and nitrogen-K ionization edge show identical near edge structures indicating a similar threefold coordination and electronic environment of the carbon and nitrogen in the synthesized material.

To summarize the data on the bulk structure, we can see that the carbon nitride system is indeed composed of graphite-like stacks, which contain less electron dense spots with at least a close to hexagonal order within the layers. This organization 


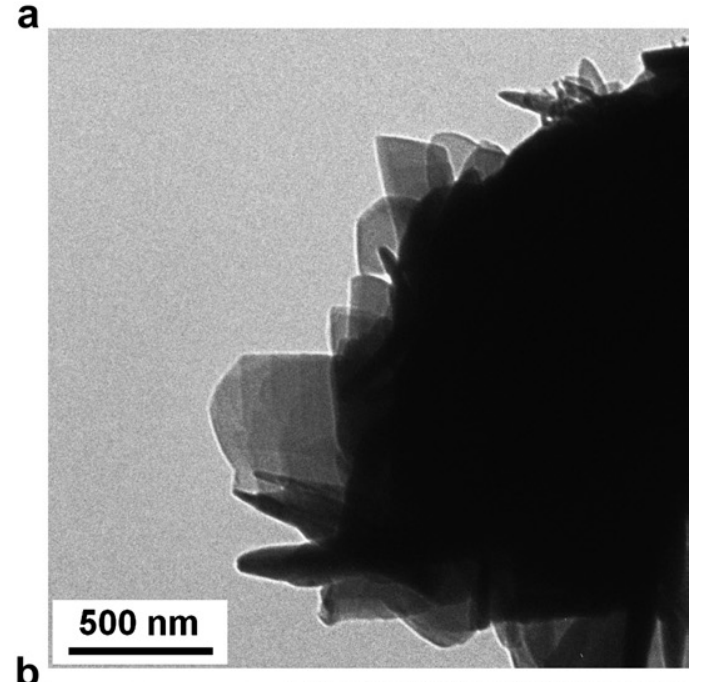

b

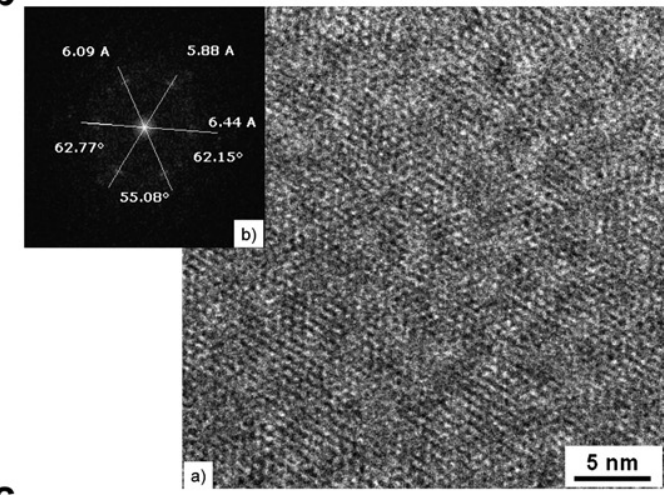

C

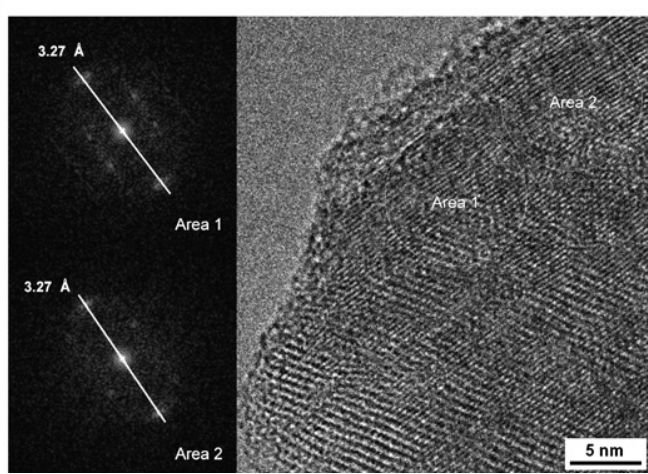

Fig. 6 (a) TEM micrograph of the crystallized $\mathrm{g}-\mathrm{C}_{3} \mathrm{~N}_{4}$. The morphology is layered, platelet-like. (b) a) In-plane organization of the condensed g- $\mathrm{C}_{3} \mathrm{~N}_{4}$ material formed by tri-s-triazine units. The power spectrum (inset b) underlines that the hexagonal symmetry is broken, indicating either connectivity defects or angularity of view. (c) Graphite-like stacking of the material visualized with HRTEM. The power spectra of the circular areas 1 and 2 reveal an inter-planar distance of $0.327 \mathrm{~nm}$ and a periodicity within the layers. Streaks due to stacking faults are visible.

obviously tolerates incomplete condensation and a number of defects, as already indicated by Schnick et al. while reporting on melon. ${ }^{26}$

\section{Electronic and optical properties of $\mathrm{g}-\mathrm{C}_{3} \mathrm{~N}_{4}$}

The special electronic properties can at least qualitatively be checked by simple UV-Vis absorption and photoluminescence

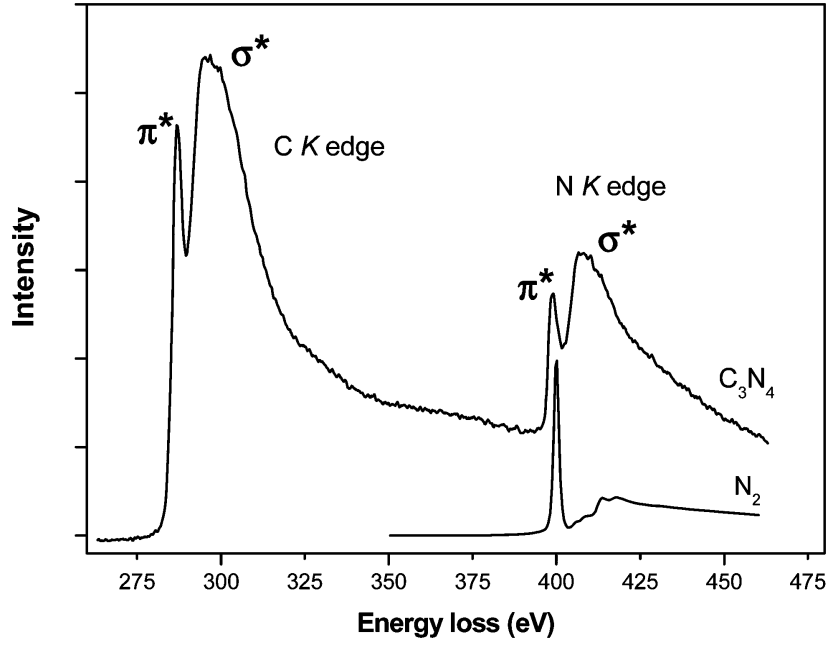

Fig. 7 EELS spectrum of carbon and nitrogen $\mathrm{K}$ edges recorded in crystalline $\mathrm{g}-\mathrm{C}_{3} \mathrm{~N}_{4}$ synthesized at $550{ }^{\circ} \mathrm{C}$. For comparison, the nitrogen- $\mathrm{K}$ ionization edge of $\mathrm{N}_{2}$ is also presented.

experiments, as already reported by a number of authors. Indeed, g- $\mathrm{C}_{3} \mathrm{~N}_{4}$ shows the typical absorption pattern of a semiconductor with a pronounced band gap at about $420 \mathrm{~nm}$, thus making the material slightly yellow. The photoluminescence spectrum (Fig. 8) sensitively depends on the degree of condensation and the packing between the layers. While the uncondensed melem still shows a PL peak maximum at around $\lambda_{\max }=366 \mathrm{~nm}$, this peak shifts for melon like materials (condensed for $4 \mathrm{~h}$ at $550{ }^{\circ} \mathrm{C}$ ) to $\lambda_{\max }=472 \mathrm{~nm}$, in agreement with lowering the optical band gap by condensation of single molecules to an extended solid material. Interestingly, the luminescence is blueshifted again when going to a more perfected packing by extended tempering $\left(600^{\circ} \mathrm{C}\right)$. This may be due to altered electronic coupling between the layers, which is however hard to calculate quantitatively.

To explain potential catalytic effects discussed below and estimate local interactions with substrate molecules, more simplified DFT calculations were performed using the Gaussian 03 package with the B3 PW91 functional also on a model

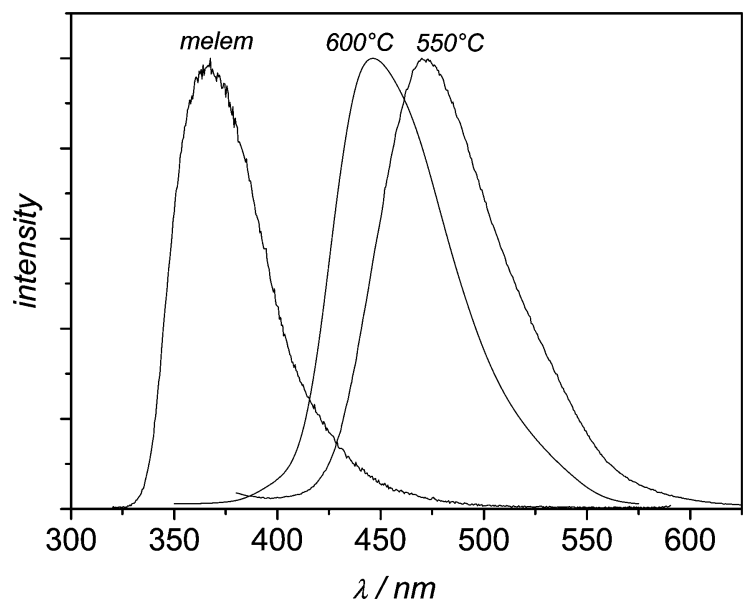

Fig. 8 Photoluminescence spectra of melem (see also ref. 25) and g- $\mathrm{C}_{3} \mathrm{~N}_{4}$ materials condensed at $550{ }^{\circ} \mathrm{C}$ and $600{ }^{\circ} \mathrm{C}$. 

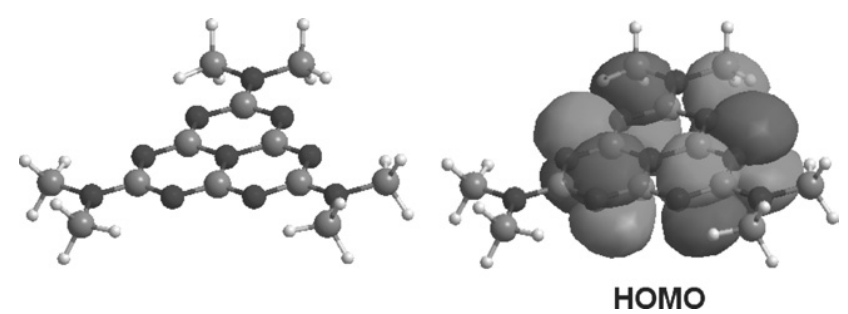

Fig. 9 Optimized geometry of the model melem ring (left) and isodensity surface of the corresponding highest occupied molecular orbital (right).

monomer/melem unit. ${ }^{39}$ The optimized geometry is shown in Fig. 9. The three highest occupied molecular orbitals (HOMOs) feature a $\pi$ symmetry, whereas HOMO -3 is an antiphase combination of the atomic orbitals describing the lone pairs of the "aromatic" nitrogen atoms. These results are in good qualitative agreement with the electronic structures of tri-s-triazine calculated by Lebreton and coworkers as early as $1984 .^{40}$ The HOMO consists exclusively of an antiphase combination of the $\mathrm{p}_{z}$ orbitals of the pyridine-like nitrogens. This is exactly the symmetry of the highest unoccupied $\pi$ type orbital in the Hückel model of benzene. It should therefore be possible to form a charge transfer complex and to transfer electron density from $\mathrm{g}-\mathrm{C}_{3} \mathrm{~N}_{4}$ to benzene, resulting in an "organic" activation of the aromatic rings. As the perfect infinite $\mathrm{g}-\mathrm{C}_{3} \mathrm{~N}_{4}$ sheet however features an electronic band structure, this activation path might only be possible on defects and termination sites of the sheet, promoting electron relocalization.

Such calculations are however not suited to have quantitative predictive power, but are just good for plausibilization, as they hold true for single molecules in vacuum, but can consider the influence of neither strong hydrogen bridges within the planes nor weak van der Waals interactions between the sheets of carbon nitride, as already discussed in context with the luminescence spectra.

\section{Synthesis of $g-C_{3} N_{4}$ nanoparticles in mesoporous silica host matrices}

It was previously stated that the liquid character of starting products also allows the synthesis of a variety of nanostructures. Nanoparticles of $\mathrm{g}-\mathrm{C}_{3} \mathrm{~N}_{4}$ were for instance obtained by nanocasting/replication of ordered mesoporous silica matrices, ${ }^{41}$ well known from the generation of corresponding carbon nanostructures. For carbon, appropriate precursors were used to fill the channel system, followed by carbonisation of the guest material and subsequent removal of the silica matrix. ${ }^{42,43}$ It was also possible to synthesize spherical high-temperature-resistant (HTR) polyimide nanoparticles and polyimide nanoplates, using monomer solutions and-in contrast to the high temperature carbonisation - modest temperatures ${ }^{44}$ Comparable to this and other templating approaches, ${ }^{45}$ a series of different mesoporous silicas with pore sizes between $8 \mathrm{~nm}$ and $60 \mathrm{~nm}$ were filled with cyanamide, and the condensation reaction was performed similar to the bulk samples. ${ }^{41}$

The successful morphological transcription of the spherical pore system was characterized by electron microscopy. Fig. 10 shows SEM images of the used silica matrix and the $\mathrm{C}_{3} \mathrm{~N}_{4}$

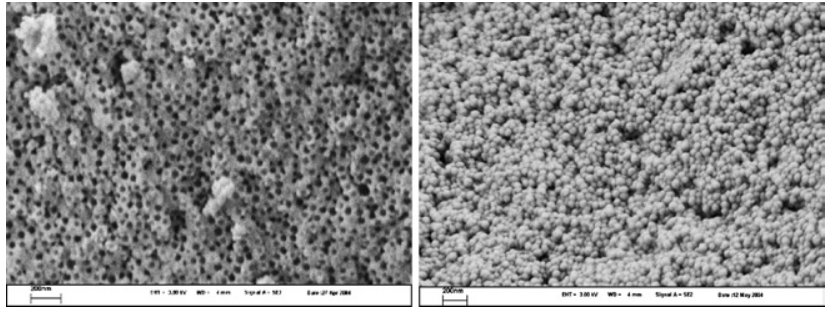

Fig. 10 SEM pictures of the used silica matrix (left) and the $\mathrm{C}_{3} \mathrm{~N}_{4}$ spheres after etching the matrix.

product found after etching the matrix. The material consists mainly of oblate particles with diameters of 50-70 nm.

It is noteworthy for the experts in the field of structural replication that we do not observe the formation of linkages or "catwalks" between the particles, owing to the fact that the original cast materials usually contain micropores which connect the large pores of the matrix with each other. ${ }^{46}$ The resulting carbonitride powder is free flowing and just consists of isolated spheres. This is different to the corresponding carbon replicas, ${ }^{42,43}$ where monolithic $1: 1$ copies rather than isolated objects were obtained. It can be speculated that the reason for this peculiarity lies in the very special architecture of $\mathrm{g}-\mathrm{C}_{3} \mathrm{~N}_{4}$, which is composed of $c a$. $1 \mathrm{~nm}$ sized melem units. These structural tectons are possibly simply too big to be formed within and reaching through the micropores.

AFM indicated that the isolated particles possess a $60 \mathrm{~nm}$ horizontal diameter and a height of $\sim 30-40 \mathrm{~nm}$, in agreement with the SEM images. The reaction product is obviously not perfectly spherical like the pore, but has an oblate shape, corresponding to the mass loss and the densification throughout the condensation process. $\mathrm{g}-\mathrm{C}_{3} \mathrm{~N}_{4}$ is a layered material, that is we have to assume that the structure looks like a stack of pancakes (the $\mathrm{C}_{3} \mathrm{~N}_{4}$ planes) filling the center of the spherical pores, with the volume at the poles simply left out for energetic, line-tension reasons.

XRD reveals the graphite-like structure of the different nanoparticles, showing the typical interlayer stacking peak. In the nano-confined reaction conditions, the interlayer reflection is shifted to slightly higher angles as compared to the bulk material, indicating a minimal shortening interlayer distance of $0.05 \AA$. No broadening of the interlayer reflection due to size effects is observed. The better packing in the nanoparticles sounds unexpected, but is a general "nano-effect" and due to the relatively smaller influence of structural defects, which are more difficult to accommodate in a macroscopic material. Thus, even for $5 \mathrm{~nm}$ particles, a quite perfectly packed structure perpendicular to the layer direction is observed. This finding however also indicates that domain sizes of bulk-g- $\mathrm{C}_{3} \mathrm{~N}_{4}$ can be very small, still featuring the observed XRD patterns.

A size effect on the electronic structure can be identified by the photoluminescence spectra. It was described that the optical bandgap is shifted towards higher energies (from $472 \mathrm{~nm}$ to 420 $\mathrm{nm}$ emission maximum) for all the synthesized nanoparticles. This may be also due to a more perfect packing and electronic coupling between the layers.

The fact that the nanoparticles are indeed composed of single, non-connected $\mathrm{C}_{3} \mathrm{~N}_{4}$ layers can be shown by intercalation 
experiments. The basic character of $g-\mathrm{C}_{3} \mathrm{~N}_{4}$ enables the convenient intercalation of strong acids by simple stirring, e.g. fluorinated carboxylic acids with two different tail lengths. ${ }^{41}$ It was nicely demonstrated that the interlayer stacking peak is indeed shifted to smaller angles corresponding to larger distances, which in addition depends on the tail length of the acid. This proves that the chemical functionality of the single nanolayers can be accessed. A broad peak at the former stacking position however indicates that the delamination is not perfect.

\section{Synthesis of mesoporous $\mathrm{g}-\mathrm{C}_{3} \mathrm{~N}_{4}$ monoliths and films}

To make $\mathrm{g}-\mathrm{C}_{3} \mathrm{~N}_{4}$ a potentially useful substitute for graphitic carbon in applications where surface is of importance (e.g. as catalytic support or for gas storage ${ }^{47}$ ), procedures to introduce porosity in the bulk nitrides are needed, exposing a large surface area and the connected chemical functionality for interface reactions. Vinu et al. reported the synthesis of mesoporous carbon nitride via nanocasting techniques, ${ }^{48}$ featuring a large surface area. The $\mathrm{C} / \mathrm{N}$ molar ratio $(\sim 5)$ however indicated loss of the vast majority of nitrogen. This process yielded a mostly amorphous network, which also enables, in contrast to the results observed for $\mathrm{C}_{3} \mathrm{~N}_{4}$, the replication of micropores, thus enabling the formation of an interconnected cast.

To extend this approach to species with high nitrogen content, the condensation of cyanamide, dicyandiamide or melamine under ammonia elimination was applied to generate mesoporous g- $\mathrm{C}_{3} \mathrm{~N}_{4}$ materials with high local order. ${ }^{39}$ Silica nanoparticles were used as easily accessible and suitable hard templates. More favorably, these silica nanoparticles could be homogeneously dispersed in the starting monomers. This is enabled by the appropriate surface interactions between the silica surface and the amine and - later in the reaction - aromatic nitrogen groups. Condensation of the monomers at elevated temperatures resulted in carbon nitride/silica hybrids, where the silica nanoparticles stay well-dispersed in a solid carbon nitride matrix. Dissolution of the silica with ammonium hydrogen fluoride solution not only revealed the full accessibility of the silica species, but also yielded various mesoporous $g-\mathrm{C}_{3} \mathrm{~N}_{4}\left(\mathrm{mpg}-\mathrm{C}_{3} \mathrm{~N}_{4}\right)$. The pore size and connectivity of these powders exactly reflect the geometric properties of the original template. Fig. 11 shows example TEM

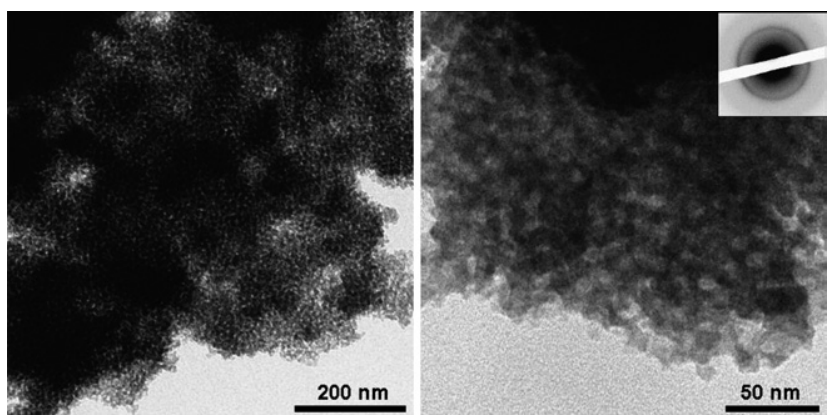

Fig. 11 TEM micrographs and selected area electron diffraction pattern of a mpg- $\mathrm{C}_{3} \mathrm{~N}_{4}$ after removal of the silica nanoparticles in two different magnifications.

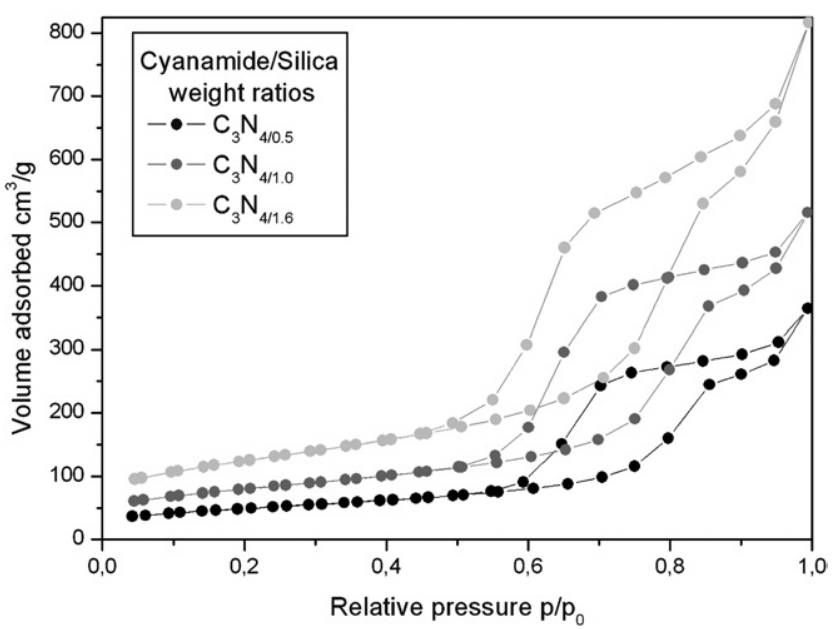

Fig. 12 Nitrogen gas adsorption isotherms for different $m p g-C_{3} N_{4}$ samples reflecting different template concentrations.

pictures of a sample with an initial cyanamide : silica mass ratio of $1: 1$ condensed for $4 \mathrm{~h}$ at $550^{\circ} \mathrm{C}$ after removal of the template.

The disordered pore system of spherical pores with a diameter of $12 \mathrm{~nm}$ can be regarded as typical for the structure of the silica sol. In addition, selected area electron diffraction proves the order of the pore walls, revealed by one intense ring corresponding to the stacking distance of $\mathrm{g}_{-} \mathrm{C}_{3} \mathrm{~N}_{4}(d=0.33 \mathrm{~nm})$.

Fig. 12 shows nitrogen adsorption/desorption isotherms of three mpg- $\mathrm{C}_{3} \mathrm{~N}_{4}$ samples synthesized using different template : precursor ratios. The curves show a pronounced hysteresis, typical of the existence of randomly connected spherical pores, only weak microporosity, and surface areas between $86 \mathrm{~m}^{2} \mathrm{~g}^{-1}$ and $439 \mathrm{~m}^{2} \mathrm{~g}^{-1}$, depending on the weight fraction of template.

Hwang and co-workers prepared in a similar fashion wellordered nanoporous graphitic carbon nitrides using a colloidal crystal array of silica nanoparticles as templates. Cyanamide as liquid precursor was infiltrated into the interstitial voids of the array and subsequently annealed to $550^{\circ} \mathrm{C}$ for $3 \mathrm{~h}$. Dissolution of the silica with aqueous HF yielded macroporous replicas exhibiting an inverse opal structure with pores of $260 \mathrm{~nm}$ in size. Furthermore XRD, IR and EDX measurements revealed the formation of an extended graphitic $\mathrm{C}_{3} \mathrm{~N}_{4}$ structure in the pore walls. $^{49}$

This macroporous graphitic carbon nitride was subsequently

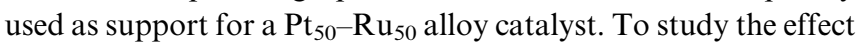
of the support on the anodic performance in direct methanol fuel cells, a ordered macroporous carbon was synthesized using the same silica template, yet exhibiting a similar macroporous structure. Interestingly, a much higher surface area was observed for the carbon material $\left(605 \mathrm{~m}^{2} \mathrm{~g}^{-1}\right)$ compared to the carbon nitride $\left(108 \mathrm{~m}^{2} \mathrm{~g}^{-1}\right)$, showing a general structural feature of carbon nitrides compared to carbon, that is, they do not exhibit microporosity. However, although macroporous $\mathrm{g}-\mathrm{C}_{3} \mathrm{~N}_{4}$ exhibited a much lower surface area than the corresponding carbon material, a higher catalytic activity of catalysts supported by this compound was reported. The higher performance of Pt$\mathrm{Ru} / \mathrm{C}_{3} \mathrm{~N}_{4}$ was thus attributed to the electronic properties of $\mathrm{C}_{3} \mathrm{~N}_{4}$, probably triggered through electron transfer from the nitrogen atoms. ${ }^{50}$ 


\section{Growth confined by the nitrogen source: mesoporous graphitic carbon nitride as a novel reaction medium for the direct synthesis of pure metal nitride nanoparticles}

Based on the availability of nanostructured carbon nitrides and the fact that the material essentially completely decomposes at $700{ }^{\circ} \mathrm{C}$ to highly reactive $\mathrm{C}$ and $\mathrm{N}$ fragments, carbon nitride can also be applied as a powerful reactant for nitride and carbide nanoparticle syntheses.

Metal nitrides in general can be generated by the conversion of metals or metal oxides into the corresponding nitrides using nitrogen sources, such as ammonia ${ }^{51}$ or hydrazine, ${ }^{52,53}$ at high temperatures. Also the use of carbon nitride as a nitrogen source was described, ${ }^{54,55}$ which was achieved by mixing metal chlorides or oxides together with carbon nitride and subsequent heating under vacuum to produce the corresponding metal nitrides. Recently it was shown that cyanamide, which inherently forms carbon nitride species during synthesis, can act as an efficient nitrogen source for the conversion of nanostructured metal oxides into the corresponding nitrides, such as metal nitride nanoparticles ${ }^{56}$ or mesoporous metal nitrides. ${ }^{57}$

When mesoporous carbon nitride is used to contact with the metal precursor, it acts both as a confinement for particle growth and a nitrogen source, and control over particle size and composition can be obtained, as is typical for nanoreactors. ${ }^{58,59}$ The mesoporous carbon nitride filled with the appropriate amounts and types of metal precursor is then heated to the decomposition temperature of the carbon nitride. Upon degradation $\mathrm{C}_{3} \mathrm{~N}_{4}$ provided the required $\mathrm{N}$ atoms, while confining the nanoparticles preventing their sintering. Thus, crystalline metal nitride nanoparticles with well controlled sizes were obtained. The temperature for these reactions is - for nitride synthesis - rather moderate, as complete decomposition of carbon nitrides occurs at $700{ }^{\circ} \mathrm{C}$.

Titanium nitride (TiN), vanadium nitride (VN) and gallium nitride $(\mathrm{GaN})$ were made in this way. These nitrides were chosen as representatives for different material properties and possible applications: TiN for its mechanical hardness as an abrasive material, VN for its catalytic activity and GaN as a III-V semiconductor for optical and electronic applications. It is important to note that the nitride nanostructures are - via the pores - essentially copies of the primary templates, here silica nanoparticles, and their size, shape and polydispersity are therefore easily adjusted.

Fig. 13 compares the original $m p g-\mathrm{C}_{3} \mathrm{~N}_{4}$ template and the as-formed narrowly distributed nanoparticles for titania. X-Ray diffraction patterns (Fig. 13d) indicate the formation of titanium nitride. The size of the titanium nitride particles was finely adjusted by different "filling rates" of the nanoreactors, related to the concentration of the precursor solutions used. Control experiments using bulk carbon nitride as a nitrogen source in contrast lead to particles with much larger diameters (up to several hundreds of nanometers) and a broad dispersity.

Fig. 14 shows the results for gallium chloride $\left(\mathrm{GaCl}_{3}\right)$ and vanadium oxytrichloride $\left(\mathrm{VOCl}_{3}\right)$ as precursors, indicating the universality of this approach.

\section{7. $\mathrm{g}-\mathrm{C}_{3} \mathrm{~N}_{4}$ for metal free coordination chemistry and metal free heterogeneous catalysis}

\section{a) Friedel-Crafts type reactions}

It was delineated above that carbon nitride is a rather electron rich organic semiconductor, possessing an experimental band gap
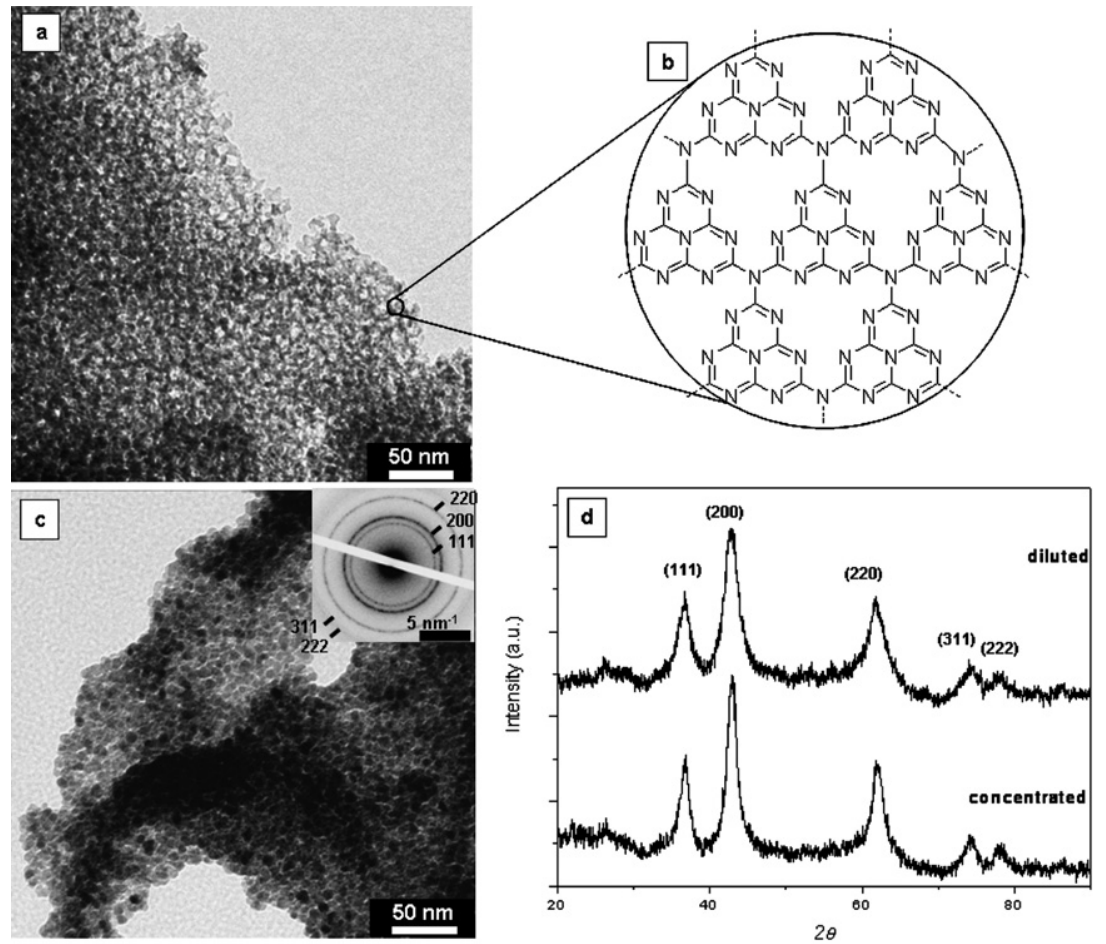

Fig. 13 TEM micrographs of the original reaction matrix $(a, b)$ and the titanium nitride nanoparticles synthesized in $\mathrm{mpg} \mathrm{C}_{3} \mathrm{~N}_{4}(\mathrm{c})$. (d) Comparative XRD patterns from concentrated and diluted precursor solutions. 

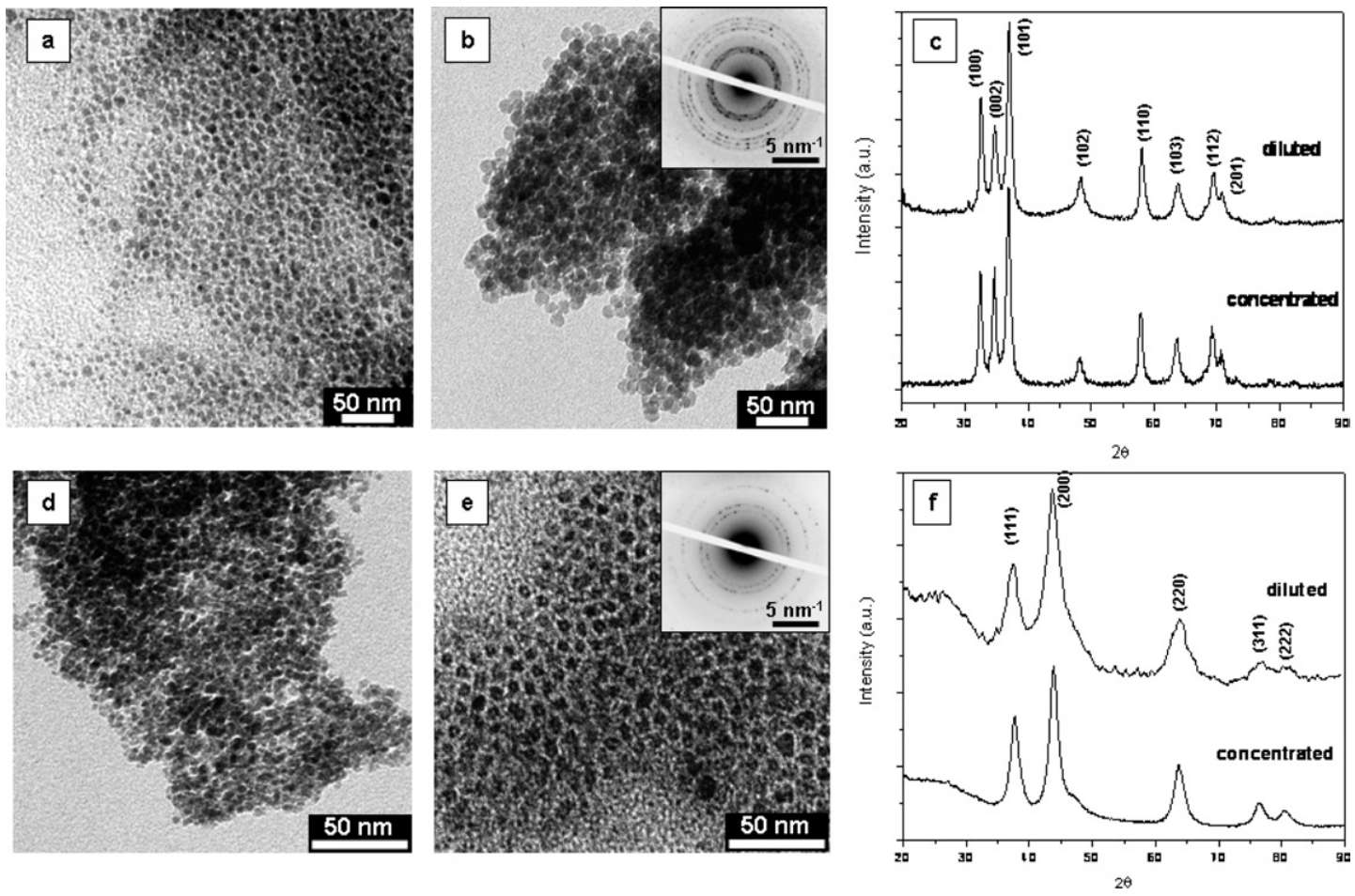

Fig. 14 Metal nitride particles observed after confinement and conversion in mesoporous carbon nitride: (a,b) well separated gallium nitride; (d,e) vanadium nitride nanoparticles obtained from concentrated and diluted precursor solutions. Corresponding XRD patterns of (c) gallium nitride and (f) vanadium nitride nanoparticles from concentrated and diluted precursor solutions, respectively.

of $2.7 \mathrm{eV}$. For graphite it is well known that its defects such as edges ${ }^{60}$ curvature $^{61}$ or doping atoms ${ }^{62}$ can induce electron relocalization in both the valence and conduction bands, making it an appropriate catalyst, as has recently been demonstrated for the example of the oxidative dehydrogenation of ethylbenzene. ${ }^{63,64}$ Due to its structure and electronic properties, mpg$\mathrm{C}_{3} \mathrm{~N}_{4}$ features almost all the prerequisites to be such a metal free heterogeneous catalyst, i.e. it has the right electronic properties, face termination for electron localization, and a high surface area.

Friedel-Crafts (FC) acylation is a typical aromatic $\mathrm{C}-\mathrm{H}$ activation process. However, usually the electrophile is activated, while activation of the nucleophile, i.e. the aromatic compound, should - in principle - result in the same outcome. Mesoporous samples of $\mathrm{C}_{3} \mathrm{~N}_{4}$ with varying surface areas were analyzed for this specific reaction, ${ }^{39}$ and it turned out that the reactivity essentially depends on both the surface area and an optimal degree of condensation. For the Friedel-Crafts reaction, tempering the carbon nitride at $600{ }^{\circ} \mathrm{C}$ and increased organization and condensation seemed to improve the catalytic activity (treatment and surface area stayed otherwise unchanged), which was interpreted as meaning that the semiconductor properties need a certain wall thickness to build up.

The great advantage of such metal-free catalysis is that it inherently allows the presence of functional groups along with the reactants or leaving groups, which otherwise usually passivate the metal catalyst. Actually the use of carboxylic acids or alcohols as electrophiles lies at the heart of current efforts to render Friedel-Crafts reactions more sustainable, which has previously proved to be rather difficult. The use of mpg- $\mathrm{C}_{3} \mathrm{~N}_{4}$ as a catalyst indeed allowed such a flexible reactant choice. In particular $\mathrm{OH}$ or $\mathrm{NH}_{2}$ groups could be used as leaving groups, thus allowing for an effective low temperature alkylation with alcohols or quaternary amines or even cyanation with urea. ${ }^{65}$ Fig. 15 depicts some of these unusual reaction pathways promoted by carbon nitride.

It is interesting to see that many of these reactions employing new functionalities for reaction indeed look biomimetic, and it is interesting to speculate why $\mathrm{C}_{3} \mathrm{~N}_{4}$ is particularly suited for those reactions. One answer may be that a number of cyanide based, nitrogen-rich, conjugated organic molecules, such as nucleic acids and porphyrins, are "molecular fossils" which existed

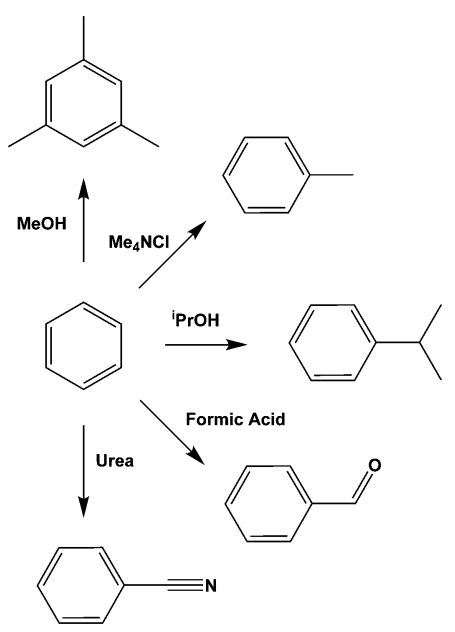

Fig. 15 Some possible Friedel-Crafts type reactions catalysed by mpg- $\mathrm{C}_{3} \mathrm{~N}_{4}$ using sustainable electrophiles. 


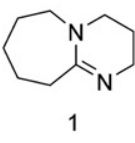

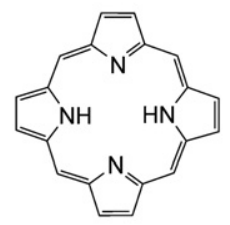

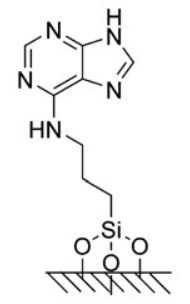

3

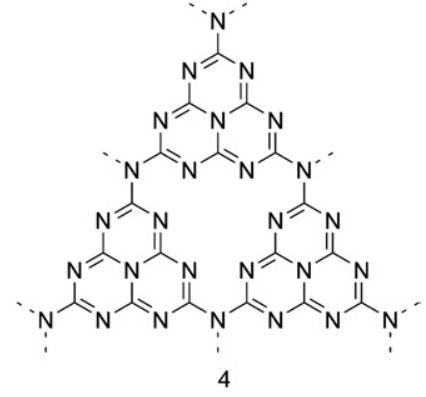

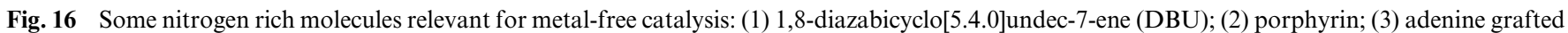
on silica; (4) idealized repetition motif of graphitic $\mathrm{C}_{3} \mathrm{~N}_{4}$.

before life began. ${ }^{66}$ The function of many enzymes is based on the special $\mathrm{N}-\mathrm{C}=\mathrm{N}$ binding motif, either as a histidine or as a porphyrin moiety or even both.

In the Rubisco enzyme for photosynthesis, a histidine is also used to fixate the $\mathrm{CO}_{2}$ as a carbamate as the first step of the cycle. ${ }^{67}$ As organic-chemical mimics, 1,8-diazabicyclo[5.4.0] undec-7-ene (DBU, Fig. 16) ${ }^{68-72}$ turned out to be ineffective, while adenine (Fig. 1) bound to mesoporous oxides was recently shown to promote $\mathrm{CO}_{2}$ fixation through a true carbamate species. ${ }^{73}$ The "multiplied" $\mathrm{N}-\mathrm{C}=\mathrm{N}$ - binding motif in $\mathrm{g}-\mathrm{C}_{3} \mathrm{~N}_{4}$ was therefore a natural choice to enable more efficient $\mathrm{CO}_{2}$ fixation and, finally, its activation.

It was indeed shown that a mesoporous $\mathrm{g}-\mathrm{C}_{3} \mathrm{~N}_{4}$ could not only fix the $\mathrm{CO}_{2}$ as a carbamate, but also activate the reaction of $\mathrm{CO}_{2}$ with benzene, finally resulting in phenol and a formal carbon monoxide. Thus, $\mathrm{CO}_{2}$ was split. ${ }^{74}$ It turned out that the reaction only took place when a sufficiently strong base was present; presumably to remove the phenol as a phenolate from the equilibrium reaction. The reaction products are free of benzoic acid, the product of a possible direct carboxylation of benzene. The only side reaction observed is the formation of biphenyl in the presence of a large excess of benzene. This is likely to result from the arylation of benzene with phenol, again a FriedelCrafts type consecutive reaction.

FTIR investigation of the catalysts after reaction is strongly indicative of the formation of a carbamate species as two new IR bands appear in the spectrum of the powder at 1597 and 1419 $\mathrm{cm}^{-1}$. Thus, it was postulated that the first step of the catalytic process involves the formation of a carbamate species, presumably on primary or secondary surface amino groups of mpg$\mathrm{C}_{3} \mathrm{~N}_{4}$ which occur as defects and for edge termination. The formed carbamate would then be well positioned to react with the benzene activated by the catalyst. Hypothetically, a formal $2+2$ addition of the aromatic $\mathrm{C}-\mathrm{H}$ bond of the benzene to the $\mathrm{C}=\mathrm{O}$ double bond would result in the formation of a hemiacetal, which could easily eliminate phenol to yield a formamide moiety. The latter would then eliminate $\mathrm{CO}$ as reported for the thermolysis of formamide. ${ }^{75}$ This is also presumably the rate

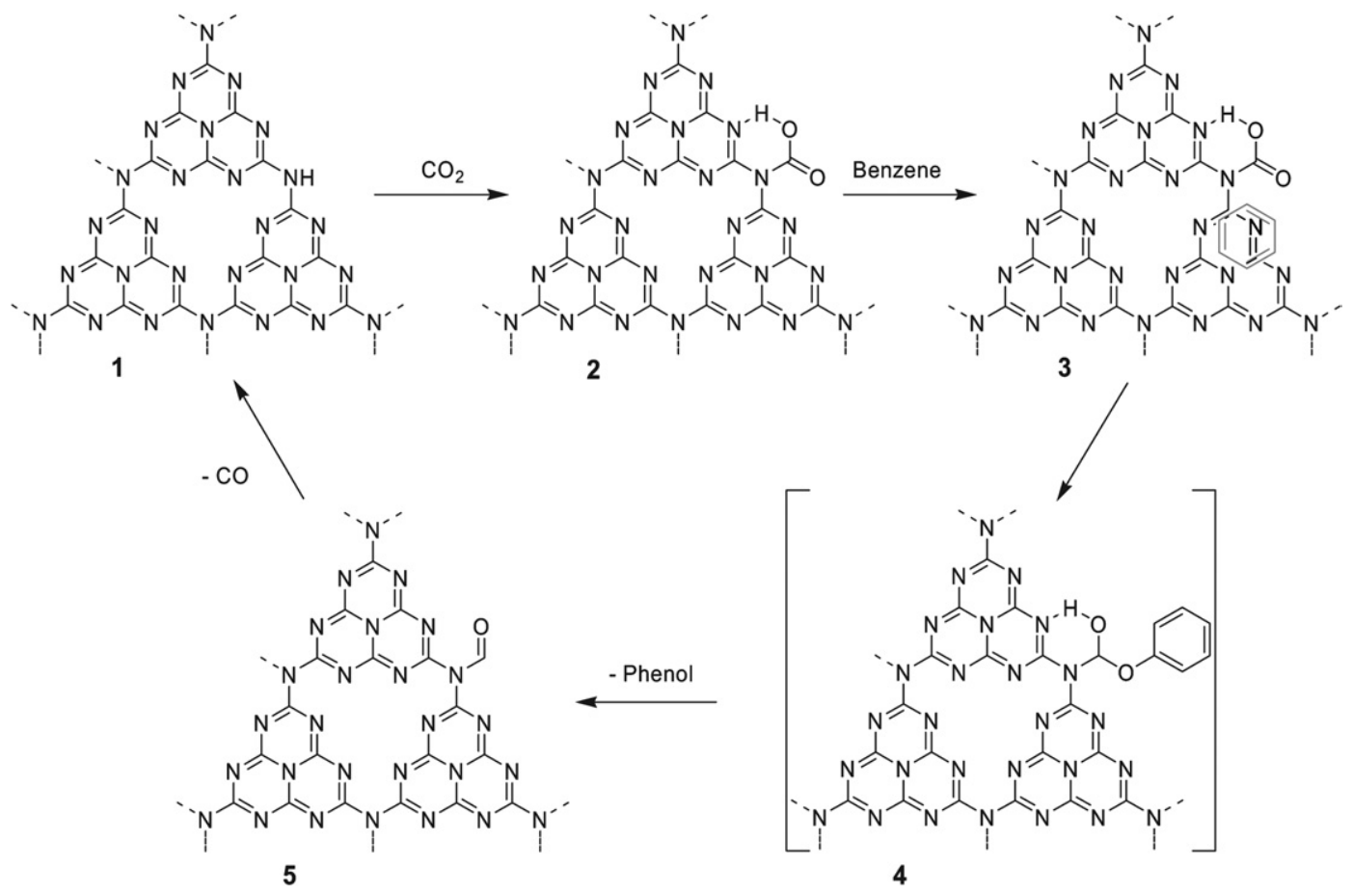

Fig. 17 Proposed reaction cycle for the formation of phenol. 


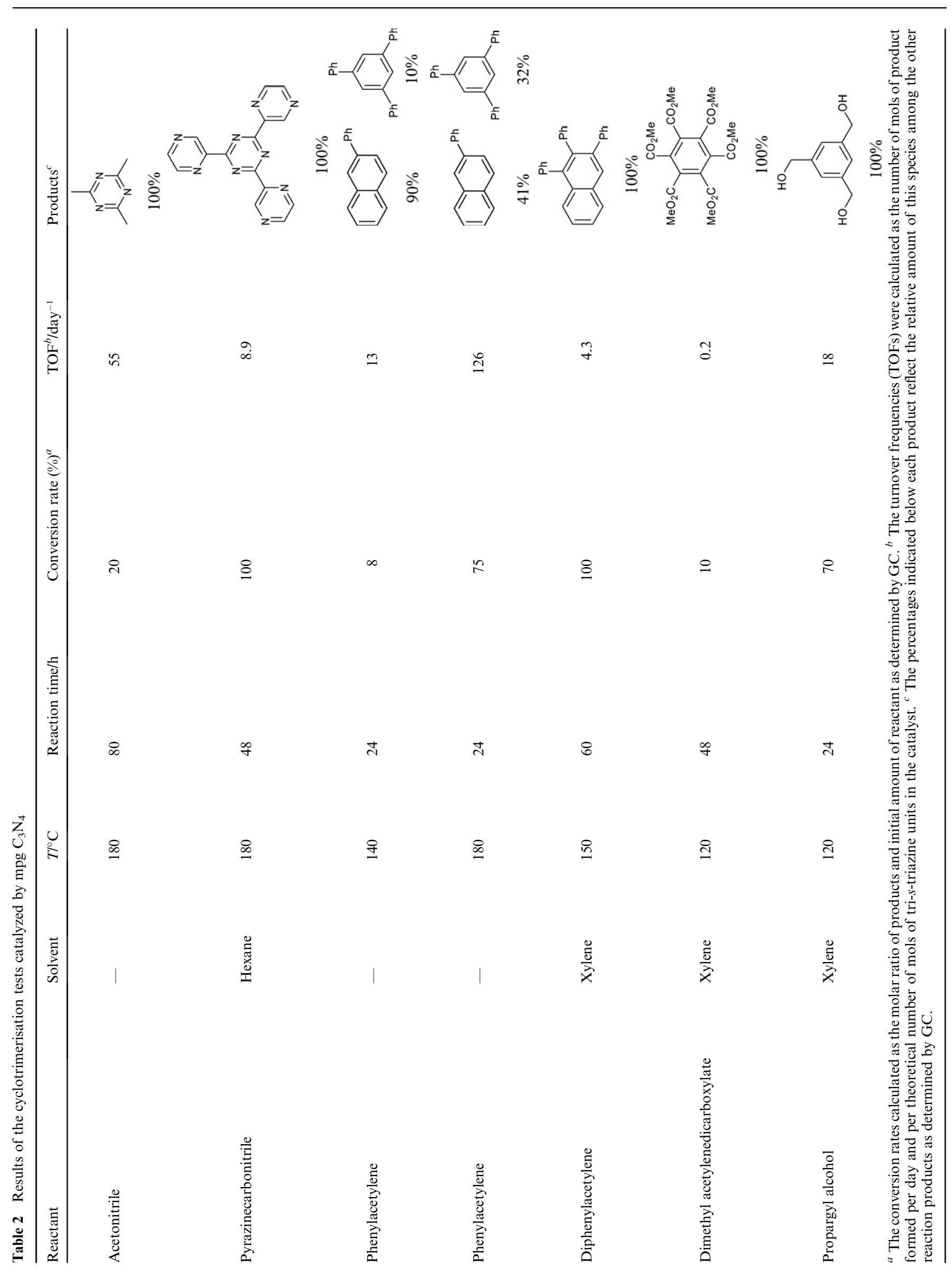


determining step. Fig. 17 illustrates this reaction pathway where $\mathrm{C}_{3} \mathrm{~N}_{4}$ plays two different roles, i.e. for binding and activating the $\mathrm{CO}_{2}$ and for activating the aromatic compound.

DFT calculations were undertaken to support single steps of the proposed mechanism. The results of these calculations indicate that the steps of the mechanism up to the phenolate elimination are exothermic under alkaline conditions.

The generated $\mathrm{CO}$ is a valuable starting product and can undergo a cascade of potential follow-up reactions. The availability of produced $\mathrm{CO}$ was checked in a bifunctional catalytic scheme, where the $\mathrm{CO}$ generated from the oxidation of benzene with $\mathrm{CO}_{2}$ was used up in a Pausen-Khand reaction ${ }^{76,77}$ with an alkene (1-hexene) and an alkyne (dimethyl acetylene dicarboxylate, DMAD).

It should be emphasised that $\mathrm{g}-\mathrm{C}_{3} \mathrm{~N}_{4}$ is both a semiconductor and a base. Depending on preparation, samples may differ in both electron doping and degree of protonation. This has to be considered when performing systematic studies, as usually only one state is most effective.

\section{b) Mesoporous graphitic carbon nitride as a catalyst for the cyclisation of functional nitriles and alkynes}

The fact that mesoporous graphitic $\mathrm{C}_{3} \mathrm{~N}_{4}$ was successfully employed to activate $\mathrm{C}=\mathrm{O}$ and the double- and triple-bond coreactants in the Pauson-Khand reaction indicated that $\mathrm{g}-\mathrm{C}_{3} \mathrm{~N}_{4}$ not only activates benzene, but also interacts with the various double and triple bond reactants. ${ }^{78}$ In this connection, g- $\mathrm{C}_{3} \mathrm{~N}_{4}$ was employed as an effective catalyst for the cyclotrimerisation of various nitriles into triazine derivatives and the cyclisation of functional alkynes. Cyclotrimerisations of triple bonds are usually very exothermic reactions because they result in the formation of an aromatic system, but practically rarely realized because of very high activation energies. This can be exemplified for the archetypical case of acetylene, where the activation energy of the concerted cyclisation mechanism towards benzene was estimated to be around $250 \mathrm{~kJ} \mathrm{~mol}^{-1} \cdot{ }^{79}$ Nevertheless, such reactions are of great synthetic significance because they permit access to functional cyclic aromatic systems.

The results of some cyclisation experiments are summarized in Table 2. The expected trimerisation or Diels-Alder products were obtained in moderate to high yields. Interestingly it was possible to demonstrate, based on both DFT evidence and surface modification of the employed catalysts, that the activation mechanism of alkenes is essentially different from that of nitriles. Indeed, while alkenes were activated via electron donation (as is the case for benzene), nitriles interacted with the edges of the $\mathrm{C}_{3} \mathrm{~N}_{4}$ sheets via multiple $\mathrm{H}$-bonding, which provided the catalyst with a very marked substrate selectivity. This was exemplified by the fact that pyrazine carbonitrile was one of the fastest reacting nitriles, while benzonitrile, which has very similar electronic properties and sterical hindrance, did not react at all under the employed conditions.

As evidenced by these selected results, mpg- $\mathrm{C}_{3} \mathrm{~N}_{4}$ acts as a multifunctional catalyst, either via its electronic properties (for the Friedel-Crafts and Diels-Alder reactions and the trimerisation of alkynes), its nucleophilic properties (for the activation of $\mathrm{CO}_{2}$ ) or its ability to form $\mathrm{H}$ bonds (for the trimerisation of nitriles), as shown in Fig. 18. Interestingly, the different catalytic

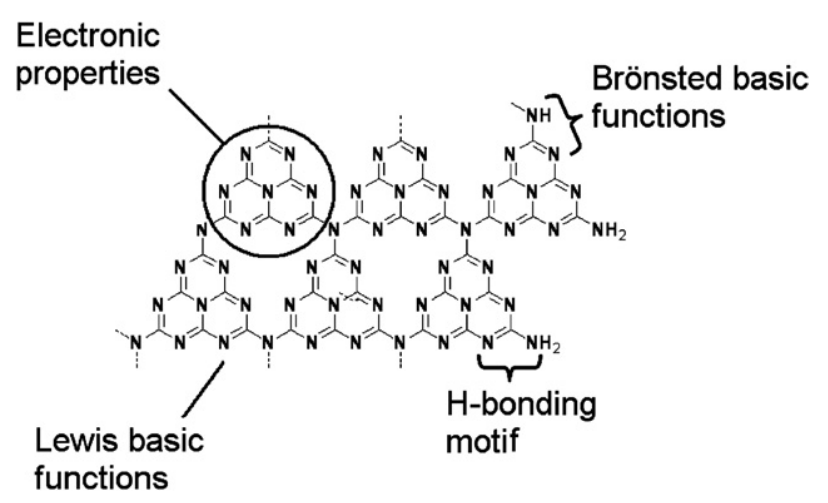

Fig. 18 Multiple functionalities of $\mathrm{C}_{3} \mathrm{~N}_{4}$ as a catalyst.

modes develop differently with the degree of condensation and with optimization of the packing. While electronic properties are best for a structure with optimal condensation and not too small structural features, all catalyses which rely on functional groups and edge termination are more efficient with less ordered, polymeric carbon nitride species and higher surface area.

The complexity of this catalyst itself is very promising. Further progress is expected, for example in the photoactivation of $\mathrm{CO}_{2}$, the activation of $\mathrm{CO}$, the $\mathrm{C}-\mathrm{H}$ activation of six-membered heterocycles, and hydrogen shift reactions in general.

\section{Summary}

In this article, we summarised the literature on, but also complemented with some of our own experiments, the knowledge of the structure and properties of one of the oldest known polymeric networks, melon and graphitic carbon nitride, made by a polymerisation process from liquid precursors. Due to the polymerisation-like approach from liquid precursors, the material is easy to shape, can be cast or coated, and results in a mechanically, thermally, and chemically stable organic semiconductor. This was exemplified by making both mesoporous monoliths and films and nanoparticles by nanocasting techniques. Above $700{ }^{\circ} \mathrm{C}$, the material vanishes without residue under the formation of highly reactive nitride species, which allows efficient nitrification of diverse metal oxides under relatively mild conditions. This was evidenced via the synthesis of well defined crystalline nitride particles.

Interestingly, the semiconductor properties allow doping, transfer of charges and the stabilisation of electrons and holes, making the material promising for a variety of catalytic schemes. This exemplifies - beside carbon - the existence of metal-free heterogeneous catalysis, otherwise only found in biology. It was proven, with the Friedel-Crafts reaction, the trimerisation of triple bonds, and especially with the splitting of $\mathrm{CO}_{2}$, that organic semiconducting polymers can support reactions which are otherwise attributed to noble and transition metals, only. In contrast to metals, these metal-free semiconductors tolerate chemical functionality (as they do not interact with it), thus clearly extending the synthetic possibilities with respect to potential leaving groups and multifunctionality.

As there are many ways to substitute carbon by nitrogen in graphite in a regular fashion, we believe that the notation "carbon nitrides" stands for a much larger family of related 
compounds (say $\mathrm{C}_{3} \mathrm{~N}_{4}, \mathrm{C}_{3} \mathrm{~N}_{2}, \mathrm{C}_{3} \mathrm{~N}, \mathrm{C}_{5} \mathrm{~N}, \mathrm{C}_{10} \mathrm{~N}_{3}$, etc.), opening again new possibilities to form polymers, scaffolds, and solid materials with new and probably exciting properties.

\section{References}

1 M. L. Cohen, Phys. Rev. B, 1985, 32, 7988.

2 A. L. Liu and M. L. Cohen, Science, 1989, 245, 841.

3 E. Kroke and M. Schwarz, Coord. Chem. Rev., 2004, 248, 493.

4 E. Horvath-Bordon, E. Kroke, I. Svoboda, H. Fuess and R. Riedel, New J. Chem., 2005, 29, 693.

5 J. Liebig, Annalen, 1834, 10, 10.

6 E. C. Franklin, J. Am. Chem. Soc., 1922, 44, 486.

7 C. E. Redemann and H. J. Lucas, J. Am. Chem. Soc., 1940, 62, 842.

8 J. Kouvetakis, A. Bandari, M. Todd, B. Wilkens and N. Cave, Chem. Mater., 1994, 6, 811.

9 H. Montigaud, B. Tanguy, G. Demazeau, I. Alves and S. Courjault, J. Mater. Sci., 2000, 35, 2547.

10 Y. Gu, L. Chen, L. Shi, J. Ma, Z. Yang and Y. Qian, Carbon, 2003, 41, 2674.

11 Z. Zhang, K. Leinenweber, M. Bauer, L. A. J. Garvie, P. F. McMillan and G. H. Wolf, J. Am. Chem. Soc., 2001, 123, 7788.

12 Q. Guo, Y. Xie, X. M. Wang, S. Lv, T. Hou and X. Liu, Chem. Phys. Lett., 2003, 380, 84

13 Q. Guo, Y. Xie, X. Wang, S. Zhang, T. Hou and S. Lv, Chem. Commun., 2004, 26.

14 T. Komatsu, J. Mater. Chem., 2001, 11, 802.

15 T. Komatsu, Macromol. Chem. Phys., 2001, 202, 19.

16 Y. J. Bai, B. Lü, Z. G. Liu, L. Li, D. L. Cui, X. G. Xu and Q. L. Wang, J. Cryst. Growth, 2003, 247, 505.

17 E. G. Gillan, Chem. Mater., 2000, 12, 3906.

18 D. R. Miller, J. R. Holst and E. G. Gillan, Inorg. Chem., 2007, 46, 2767.

19 J. L. Zimmerman, R. Williams and V. N. Khabashesku, Nano Lett., 2001, 1, 731.

20 X. F. Lu, L. G. Gai, D. L. Cui, Q. L. Wang, X. Zhao and X. T. Tao, Mater. Lett., 2007, 61, 4255.

$21 \mathrm{~J} . \mathrm{Li}, \mathrm{C}$. B. Cao and H. S. Zhu, Nanotechnology, 2007, 18, 115605.

22 S. Tragl, K. Gibson, J. Glaser, V. Duppel, A. Simon and H. J. Meyer, Solid State Commun., 2007, 141, 529.

23 Y. C. Zhao, D. L. Lu, H. W. Zhou, Y. J. Tian and O. Yanagisawa, J. Mater. Sci., 2005, 40, 2645.

24 B. V. Lotsch and W. Schnick, Chem. Mater., 2006, 18, 1891.

25 B. Jürgens, E. Irran, J. Senker, P. Kroll, H. Müller and W. Schnick, J. Am. Chem. Soc., 2003, 125, 10288.

26 B. V. Lotsch, M. Doeblinger, J. Sehnert, L. Seyfarth, J. Senker, O. Oeckler and W. Schnick, Chem.-Eur. J., 2007, 13, 4969.

27 C. Niu, Y. Z. Lu and C. M. Lieber, Science, 1993, 261, 334.

28 L. P. Guo, Y. Chen, E. G. Wang, L. Li and Z. X. Zhao, Chem. Phys. Lett., 1997, 268, 26.

29 A. K. M. S. Chowdury, D. C. Cameron, M. S. J. Hashmi and J. M. Gregg, J. Mater. Res., 1999, 14, 2359.

30 X. D. Bai, D. Y. Zhong, G. Y. Zhang, Y. C. Ma, S. Liu, E. G. Wang, Y. Chen and D. T. Shaw, Appl. Phys. Lett., 2001, 79, 1552.

31 E. Kroke, M. Schwarz, E. Horath-Bordon, P. Kroll, B. Noll and A. D. Norman, New J. Chem., 2002, 26, 508.

32 M. Groenewolt, PhD Thesis, University of Potsdam, 2004.

33 S. J. Clark, M. D. Segall, C. J. Pickard, P. J. Hasnip, M. J. Probert, K. Refson and M. C. Payne, Z. Kristallogr., 2005, 220, 567.

34 B. V. Lotsch and W. Schnick, Chem.-Eur. J., 2007, 13, 4956.

35 J. Sehnert, K. Baervinkel and J. Senker, J. Phys. Chem. B, 2007, 111, 10671.

36 W. Ruland and B. Smarsly, J. Appl. Crystallogr., 2002, 35, 624.

37 M. Kawaguchi and K. Nozaki, Chem. Mater., 1995, 7, 257.

38 E. Raymundo-Pinero, D. Cazorla-Amoros, A. Linares-Solano, J. Find, U. Wild and R. Schlögl, Carbon, 2002, 40, 597.

39 F. Goettmann, A. Fischer, A. Thomas and M. Antonietti, Angew. Chem., Int. Ed., 2006, 45, 4467.

40 M. Shahbaz, S. Urano, P. R. Lebreton, M. A. Rossman, R. S. Hosmane and N. J. Leonard, J. Am. Chem. Soc., 1984, 106, 2805.
41 M. Groenewolt and M. Antonietti, Adv. Mater., 2005, 17, 1789.

42 R. Ryoo, S. H. Joo, M. Kruk and M. Jaroniec, Adv. Mater., 2001, 13, 677; R. Ryoo, S. H. Joo and S. Jun, J. Phys. Chem. B, 1999, 103, 7743 .

43 A. H. Lu, W. Schmidt, N. Matoussevitch, H. Bonnemann, B. Spliethoff, B. Tesche, E. Bill, W. Kiefer and F. Schueth, Angew. Chem., Int. Ed., 2004, 43, 4303.

44 M. Groenewolt, A. Thomas and M. Antonietti, Macromolecules, $2004,37,4360$.

45 A. Thomas, F. Goettmann and M. Antonietti, Chem. Mater., 2008, 20, 738 .

46 B. Smarsly, C. Göltner, M. Antonietti, W. Ruland and E. Hoinkis, J. Phys. Chem. B, 2001, 105, 831 .

47 X. D. Bai, D. Y. Zhong, G. Y. Zhang, X. C. Ma, S. Liu, E. G. Wang, Y. Chen and D. T. Shaw, Appl. Phys. Lett., 2001, 79, 1552.

48 A. Vinu, K. Ariga, T. Mori, T. Nakanishi, S. Hishita, D. Golberg and Y. Bando, Adv. Mater., 2005, 17, 1648.

49 S. H. Hwang, S. H. Lee and J. S. Yu, Appl. Surf. Sci., 2007, 253, 5656.

50 M. S. Kim, S. H. Hwang and J. S. Yu, J. Mater. Chem., 2007, 17, 1656.

51 J. B. Claridge, A. P. E. York, A. J. Brungs and M. L. H. Green, Chem. Mater., 2000, 12, 132.

52 K. T. Jacob, R. Verman and R. M. Mallya, J. Mater. Sci., 2002, 37, 4465.

53 K. W. Vogt, L. A. Naugher and P. A. Kohl, Thin Solid Films, 1995, 256, 106.

54 M. Kawaguchi and K. Nozaki, Chem. Mater., 1995, 7, 257.

55 H. Z. Zhao, M. Lei, X. Yang, J. K. Jian and X. L. Chen, J. Am. Chem. Soc., 2005, 127, 15722.

56 J. Buha, I. Djerdj, M. Antonietti and M. Niederberger, Chem. Mater., $2007,19,3499$.

57 A. Fischer, M. Antonietti, A. Thomas and F. Goettmann, ChemSusChem, 2008, in press.

58 A. Fischer, M. Antonietti and A. Thomas, Adv. Mater., 2007, 19, 264.

59 A. Fischer, PhD Thesis, Potsdam, 2008.

60 T. Enoki and Y. Kobayashi, J. Mater. Chem., 2005, 15, 3999.

61 S. Tomita, T. Sakurai, H. Ohta, M. Fujii and S. Hayashi, J. Chem. Phys., 2001, 114, 7477

62 M. Endo, T. Hayashi, S. H. Hong, T. Enoki and M. S. Dresselhaus, J. Appl. Phys., 2001, 90, 5670.

63 D. S. Su, N. Maksimova, J. J. Delgado, N. Keller, G. Mestl, M. J. Ledoux and R. Schloegl, Catal. Today, 2005, 102, 110.

64 J. A. Macia-Agullo, D. Cazorla-Amoros, A. Linares-Solano, U. Wild, D. S. Su and R. Schloegl, Catal. Today, 2005, 102, 248.

65 F. Goettmann, A. Fischer, M. Antonietti and A. Thomas, Chem. Commun., 2006, 4530.

66 C. Laporte, P. Baules, A. Laporterie, J. R. Desmurs and J. Dubac, C. R. Acad. Sci., Ser. IIc, 1998, 1, 141.

67 N. Aylward and N. Bofinger, Origins Life Evol. Biosphere, 2005, 35, 345.

68 W. W. Cleland, T. J. Andrews, S. Gutteridge, F. C. Hartman and G. H. Lorimer, Chem. Rev., 1998, 98, 549.

69 M. Costa, G. P. Chiusoli, D. Taffurelli and G. Dalmonego, J. Chem. Soc., Perkin Trans. 1, 1998, 1541.

70 E. Haruki, M. Arakawa, Matsumur.N, Y. Otsuji and E. Imoto, Chem. Lett., 1974, 427.

71 W. D. McGhee, D. P. Riley, M. E. Christ and K. M. Christ, Organometallics, 1993, 12, 1429

72 T. Mizuno, J. Takahashi and A. Ogawa, Tetrahedron, 2003, 59, 1327.

73 R. Srivastava, D. Srinivas and P. Ratnasamy, Microporous Mesoporous Mater., 2006, 90, 314.

74 F. Goettmann, A. Thomas and M. Antonietti, Angew. Chem., Int. Ed., 2007, 46, 2717.

75 R. A. Back and J. C. Boden, Trans. Faraday Soc., 1971, 67, 88.

76 I. Nakamura and Y. Yamamoto, Chem. Rev., 2004, 104, 2127.

77 J. Blanco-Urgoiti, L. Anorbe, L. Perez-Serrano, G. Dominguez and J. Perez-Castells, Chem. Soc. Rev., 2004, 33, 32.

78 F. Goettmann, A. Fischer, M. Antonietti and A. Thomas, New J. Chem., 2007, 31, 1455.

79 A. Ioffe and S. Shaik, J. Chem. Soc., Perkin Trans. 2, 1992, 2101. 